\title{
Retroperitoneal Sarcomas: An Update on the Diagnostic Pathology Approach
}

\author{
Joon Hyuk Choi ${ }^{1, *(1)}$ and Jae Y. Ro ${ }^{2}$ \\ 1 Department of Pathology, Yeungnam University College of Medicine, Daegu 42415, Korea \\ 2 Department of Pathology and Genomic Medicine, Houston Methodist Hospital, Weill Medical College \\ of Cornell University, Houston, TX 77030, USA; JaeRo@houstonmethodist.org \\ * Correspondence: joonhyukchoi@ynu.ac.kr; Tel.: +82-53-620-3335; Fax: +82-53-656-1429
}

Received: 20 July 2020; Accepted: 26 August 2020; Published: 27 August 2020

\begin{abstract}
Retroperitoneal sarcomas are a heterogenous group of rare tumors arising in the retroperitoneum. Retroperitoneal sarcomas comprise approximately $10 \%$ of all soft tissue sarcomas. Though any soft tissue sarcoma histologic types may arise in the retroperitoneal space, liposarcoma (especially well-differentiated and dedifferentiated types) and leiomyosarcoma do so most commonly. Retroperitoneal sarcomas are diagnostically challenging, owing to their diversity and morphological overlap with other tumors arising in the retroperitoneum. An accurate diagnosis is necessary for correct management and prognostication. Herein, we provide an update on the diagnostic approach to retroperitoneal sarcomas and review their key histologic findings and differential diagnoses.
\end{abstract}

Keywords: retroperitoneal space; sarcoma; pathology; liposarcoma; leiomyosarcoma

\section{Introduction}

Soft tissue sarcomas are rare malignant mesenchymal tumors that account for less than $1 \%$ of all malignant tumors. The etiology of most soft tissue tumors is unknown. In rare cases $(<10 \%)$, genetic factors, environmental factors, irradiation, viral infections, and immunodeficiency may be associated with the development of soft tissue sarcomas [1]. Soft tissue tumors have been classified predominantly based on the line of differentiation - that is, which normal cell type the neoplastic cells most closely resemble [2]. The 2020 World Health Organization (WHO) classifies soft tissue tumors into 12 subtypes according to their lineage: (1) adipocytic tumors, (2) fibroblastic and myofibroblastic tumors, (3) so-called fibrohistiocytic tumors, (4) vascular tumors, (5) pericytic (perivascular) tumors, (6) smooth muscle tumors, (7) skeletal muscle tumors, (8) gastrointestinal stromal tumors, (9) chondro-osseous tumors, (10) peripheral nerve sheath tumors, (11) tumors of uncertain differentiation, and (12) undifferentiated small round cell sarcomas [3].

Primary retroperitoneal soft tissue tumors constitute a heterogenous group of neoplasms. Though benign lesions typically predominate over malignant lesions elsewhere in the body, malignant lesions of the retroperitoneum are roughly four times more frequent than benign lesions [4]. Around 10\% of all sarcomas occur in the retroperitoneum. The diagnosis of retroperitoneal tumors is complicated by (1) a large number of tumor types, (2) morphological overlap between various tumor types, and (3) the increasing use of minimally invasive biopsy techniques with very limited tissue. An accurate diagnosis is crucial for correct management and prognostication. Herein, we review the diagnostic pathology approach to retroperitoneal sarcomas and their updated histological and molecular features introduced by the 2020 WHO classification of soft tissue tumors. 


\section{Diagnostic Pathology Approach to Retroperitoneal Tumors}

\subsection{Anatomy of the Retroperitoneum}

The retroperitoneum is a complex anatomic compartment. The retroperitoneal space is bound superiorly by the 12th rib and vertebra, inferiorly by the sacrum and iliac crest, anteriorly by the peritoneum, posteriorly by the posterior abdominal wall, and laterally by the peripheral margin of the quadratus lumborum muscles [5]. The retroperitoneal space contains the esophagus, pancreas (except tail), duodenum (second and third parts), ascending and descending colon, rectum, adrenal glands, kidneys, ureter, aorta, inferior vena cava, lymph nodes, and nerve roots. Loose connective tissue is present between the organs. The retroperitoneal space is potentially large and, therefore, retroperitoneal tumors can grow considerably before manifesting clinical signs and symptoms.

Some sarcomas arise more commonly within the retroperitoneum than others. Sarcomas that occur relatively commonly versus rarely are shown in Table 1 . The most common retroperitoneal sarcomas are liposarcoma (specifically well-differentiated and dedifferentiated subtypes) and leiomyosarcoma [6]. Sarcomas arising within the retroperitoneum may be infiltrative and therefore difficult to manage surgically. A thorough understanding of the anatomy of the retroperitoneum is necessary to establish a working differential diagnosis and aid preoperative planning.

Table 1. Relatively common and rare sarcomas arising in the retroperitoneum.

\begin{tabular}{ll}
\hline \multicolumn{1}{c}{ Relatively Common Sarcomas } & \multicolumn{1}{c}{ Rare Sarcomas } \\
\hline & Solitary fibrous tumor (malignant) \\
& Inflammatory myofibroblastic tumor \\
Liposarcoma & Rhabdomyosarcoma \\
(well-differentiated and dedifferentiated subtypes) & MPNST \\
Leiomyosarcoma & Extraskeletal osteosarcoma \\
& Synovial sarcoma \\
& Desmoplastic small round cell tumor \\
& PEComa (malignant) \\
& Undifferentiated pleomorphic sarcoma \\
& Extraskeletal Ewing sarcoma \\
\hline
\end{tabular}

MPNST, malignant peripheral nerve sheath tumor; PEComa, perivascular epithelioid cell tumor.

\subsection{Clinical and Imaging Considerations}

The majority of retroperitoneal sarcomas are large at presentation; indeed, nearly $50 \%$ are larger than $20 \mathrm{~cm}$ at diagnosis [7]. Symptoms secondary to retroperitoneal lesions appear late in the course of disease and are associated with the displacement of organs and obstructive phenomena [8]. Since retroperitoneal sarcomas often involve vital structures, complete surgical resection is often not possible. Therefore, the overall prognosis of retroperitoneal sarcomas is worse than that of sarcomas in the extremities. A variety of imaging techniques, including ultrasonography, computed tomography $(\mathrm{CT})$, and magnetic resonance imaging (MRI), may be used to assess retroperitoneal tumors. Radiologic imaging plays a key role in the evaluation of tumors arising in this region. Imaging provides useful information for identifying, localizing, and characterizing the tumors, formulating the differential diagnosis, and planning for surgical resection.

Pathologists should be aware of the patient's clinical history that might help point towards a certain differential diagnosis. Radiation-associated sarcomas represent approximately $5 \%$ of all sarcomas. The most common histologic subtypes of radiation-associated sarcomas include angiosarcoma, leiomyosarcoma, extraskeletal osteosarcoma, malignant peripheral nerve sheath tumor (MPNST), and undifferentiated sarcoma [9]. Some types of soft tissue tumors occur on a familial or inherited basis. For example, in around $5-10 \%$ of patients with neurofibromatosis type 1 (NF1), MPNSTs develop, usually in a benign nerve sheath tumor [10]. A combination of the clinical history and radiographic findings can be helpful in the differential diagnosis of retroperitoneal tumors $[11,12]$. 


\subsection{Retroperitoneal Tumor Specimen Handling}

Orienting resected specimens of retroperitoneal tumors is often complicated and proper handling of resection specimens by pathologists is crucial for diagnostic accuracy. When a specimen is submitted, it is necessary to discuss the case with the surgeon to orient the specimen correctly and to identify the true margins [13]. Closest resection margins should be inked. The margin sections are taken perpendicular to the inked surface to assess the distance from the tumor to margin. An appropriate number of blocks from the tumor is required and generally determined by a useful rule of thumb that suggests one section be submitted for every $1 \mathrm{~cm}$ of the maximum diameter of the tumor [14]. In addition, it is helpful to reserve fresh tumor tissue for electron microscopy, cytogenetic analysis, and other special studies.

Areas with differences in the gross appearance (e.g., hemorrhagic, necrotic, fleshy, fibrous, mucoid, or gritty) are of particular importance to pathologists. Furthermore, sections from any foci within the tumor that look different from other areas of the tumor should be submitted. When approaching a retroperitoneal pleomorphic sarcoma, extensive sampling should be performed to search for diagnostic clues (e.g., lipoblasts, myxoid stroma, or osteoid matrix) [15].

\subsection{Histologic Evaluation}

The first and most important step in reaching a correct diagnosis is careful scrutiny of conventionally stained sections at low-power magnification [16]. A pattern-based approach is a useful technique that substantially aids the diagnostic process. At low-power magnification, the degree of cellularity, growth (architectural) pattern, tumor cell appearances, and stroma characteristics should be examined. Retroperitoneal mesenchymal tumors can be categorized based on tumor cell morphology into four groups: spindle cell, epithelioid cell, round cell, and pleomorphic cell (Table 2). Growth patterns vary and include fascicular, storiform, palisading, rosettes, lobular, nests, sheets, and biphasic. Tumor cell morphology and growth patterns are helpful for narrowing potential differential diagnoses.

Table 2. Pattern and additional findings of retroperitoneal mesenchymal tumors.

\begin{tabular}{|c|c|}
\hline Pattern & Tumor Types \\
\hline Spindle cell & $\begin{array}{l}\text { Leiomyosarcoma } \\
\text { Solitary fibrous tumor } \\
\text { Inflammatory myofibroblastic tumor } \\
\text { MPNST } \\
\text { Monophasic synovial sarcoma }\end{array}$ \\
\hline Round cell & $\begin{array}{l}\text { Poorly differentiated synovial sarcoma } \\
\text { Desmoplastic small round cell tumor } \\
\text { Extraskeletal Ewing sarcoma }\end{array}$ \\
\hline Epithelioid cell & $\begin{array}{l}\text { Epithelioid inflammatory myofibroblastic sarcoma } \\
\text { Epithelioid MPNST } \\
\text { PEComa }\end{array}$ \\
\hline Pleomorphic cell & $\begin{array}{l}\text { Dedifferentiated liposarcoma } \\
\text { Pleomorphic leiomyosarcoma } \\
\text { Pleomorphic rhabdomyosarcoma } \\
\text { Undifferentiated pleomorphic sarcoma }\end{array}$ \\
\hline Adipocytic component & $\begin{array}{l}\text { Liposarcoma (well differentiated, dedifferentiated, myxoid, and pleomorphic subtype) } \\
\text { Lipomatous (fat-forming) solitary fibrous tumor }\end{array}$ \\
\hline Prominent inflammatory cells & $\begin{array}{l}\text { Inflammatory well-differentiated liposarcoma } \\
\text { Inflammatory myofibroblastic tumor }\end{array}$ \\
\hline Tumor osteoid and bone & Extraskeletal osteosarcoma \\
\hline
\end{tabular}

Histological assessment of retroperitoneal mesenchymal tumors remains a challenge as their morphology frequently overlaps with several other tumors and because some lack distinguishing immunohistochemical markers. Malignant soft tissue tumors are generally characterized by nuclear atypia, pleomorphism, increased mitoses, granular tumor necrosis [17], and infiltrative margins. 
Some tumors have characteristic nuclear (e.g., cigar-shaped, blunt-ended nuclei in leiomyosarcoma), cytoplasmic (e.g., clear or eosinophilic granular in PEComa), and stromal features (e.g., prominent inflammatory cell infiltration in inflammatory well-differentiated liposarcoma). The presence of lipoblasts and osteoid matrix can be a diagnostic clue in liposarcoma and osteosarcoma, respectively. An understanding of tumor cell morphology, growth patterns, cytoplasmic features, and stromal features can facilitate proper diagnosis. Histological typing alone does not provide sufficient information for predicting the clinical course of disease [1]. Grading and staging are the two most important prognostic and predictive factors. The FNCLCC (Fédération nationale des centres de lutte contre le cancer) grading and TNM (tumor, lymph node, metastasis) staging system for sarcomas are widely used $[6,18]$.

\subsection{Immunohistochemistry}

Many types of soft tissue tumors lack distinctive morphological features and have an uncertain line of differentiation. Immunohistochemistry plays a critical role in identifying the line of differentiation and serves as a surrogate for underlying molecular genetic alterations.

Although many immunohistochemical markers have limited specificities, antibodies directed against protein correlates of specific molecular genetic alterations have been recently developed [19,20].

Useful immunohistochemical markers for retroperitoneal sarcomas include SMA, desmin, myogenin, CD34, S100 protein, MDM2, CDK4, STAT6, ALK, CD99, H3K27me3, NKX2.2, TLE1, SOX10, melanocytic markers (e.g., HMB-45, melan-A), cyclin D1, and epithelial markers (e.g., cytokeratin, EMA) (Table 3). An appropriate immunohistochemical panel is necessary for accurate diagnosis. Pathologists should interpret immunohistochemical findings carefully in the context of clinical and histological findings. 
Table 3. Immunohistochemistry of selected retroperitoneal mesenchymal tumors.

\begin{tabular}{|c|c|c|c|c|c|c|c|c|c|}
\hline & $\begin{array}{l}\text { Liposarcoma } \\
\text { (Well-Differentiated/Dedifferentiated) }\end{array}$ & $\begin{array}{l}\text { Solitary Fibrous } \\
\text { Tumor }\end{array}$ & $\begin{array}{c}\text { Inflammatory } \\
\text { Myofibroblastic } \\
\text { Tumor } \\
\end{array}$ & Leiomyosarcoma & MPNST & $\begin{array}{l}\text { Synovial } \\
\text { Sarcoma }\end{array}$ & DSRCT & PEComa & $\begin{array}{c}\text { Extraskeletal } \\
\text { Ewing } \\
\text { Sarcoma } \\
\end{array}$ \\
\hline SMA & - (a) & $+/-$ & $+/-$ & + & - & - & - & + & - \\
\hline Desmin & - (a) & - & $+1-$ & + & - & - & + & $+/-$ & - \\
\hline CD34 & - & + & $+/-$ & - & + & - & - & - & - \\
\hline S100 protein & $+/-$ & - & - & - & + & $+/-$ & - & $+/-$ & $+/-$ \\
\hline MDM2 & + & - & - & - & - (e) & - & - & - & - \\
\hline CDK4 & + & - & - & - & - & - & - & - & - \\
\hline STAT6 & - (b) & $+(\mathrm{d})$ & - & - & - & - & - & - & - \\
\hline ALK & - & - & + & - & $-^{(\mathrm{f})}$ & - & - & - & - \\
\hline CD99 & - & + & - & - & - & + & + & - & + \\
\hline H3К27me3 & Retained $^{(\mathrm{c})}$ & Retained & NA & Retained & Loss $(\mathrm{g})$ & Retained $^{(\mathrm{h})}$ & NA & NA & Retained \\
\hline NKX2.2 & - & - & - & - & - & $-{ }^{(\mathrm{i})}$ & $-(\mathrm{j})$ & - & + \\
\hline TLE1 & - & $+/-$ & - & - & $+/-$ & + & - & - & - \\
\hline SOX10 & - & - & - & - & + & - & - & - & - \\
\hline WT1 & - & - & - & - & - & - & + & - & - \\
\hline $\begin{array}{l}\text { HMB-45, } \\
\text { melan-A }\end{array}$ & - & - & - & - & - & - & - & + & - \\
\hline $\begin{array}{l}\text { Cytokeratin, } \\
\text { EMA }\end{array}$ & - & $+/-$ & $+/-$ & $+/-$ & - & + & + & - & $+/-$ \\
\hline
\end{tabular}

MPNST, malignant peripheral nerve sheath tumor; DSRCT, desmoplastic small round cell tumor; PEComa, perivascular epithelioid cell tumor; + , positive staining; $+/-$, focal or variable staining; -, negative staining; NA, no available data; (a) can be expressed in well-differentiated and dedifferentiated liposarcoma, (b) may be expressed in a subset of dedifferentiated

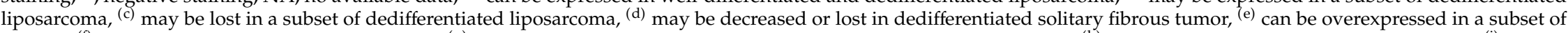
MPNST, ${ }^{(\mathrm{f})}$ may be expressed in a subset of MPNST, ${ }^{(\mathrm{g})}$ lost in approximately $50 \%$ of MPNSTs (in $90 \%$ of high-grade MPNSTs), ${ }^{(\mathrm{h})}$ may be lost in a subset of synovial sarcoma, ${ }^{(\mathrm{i})}$ may be expressed in a subset of poorly differentiated synovial sarcoma, (j) may be expressed in a subset of DSRCT. 


\subsection{Molecular Testing}

Soft tissue sarcomas can be divided broadly into two genetic classes: (1) simple karyotype sarcomas associated with a recurrent mutation or translocation (e.g., synovial sarcoma, Ewing sarcoma) and (2) complex karyotype sarcomas with numerous chromosomal aberrations but a general lack of recurrent mutations (e.g., pleomorphic liposarcoma, leiomyosarcoma, MPNST) [21-23]. Specific genetic alterations identified in retroperitoneal sarcomas are summarized in Table 4 [24-30].

Table 4. Cytogenetic and molecular alterations in selected retroperitoneal mesenchymal tumors.

\begin{tabular}{|c|c|c|}
\hline Tumor Types & Cytogenetic Alterations & Molecular Alterations \\
\hline Well-differentiated liposarcoma & $\begin{array}{l}\text { Supernumerary ring or giant marker } \\
\text { chromosome(s) }\end{array}$ & $\begin{array}{l}\text { MDM2 amplification, other } \\
\text { co-amplified genes CDK4, } \\
\text { HMGA2, TSPAN31, YEATSA4, } \\
\text { CPM, FRS2 }\end{array}$ \\
\hline Dedifferentiated liposarcoma & $\begin{array}{l}\text { Supernumerary ring or giant marker } \\
\text { chromosome(s) }\end{array}$ & $\begin{array}{l}\text { MDM2 amplification, other } \\
\text { co-amplified genes CDK4, JUN, } \\
T E R T, C P M, M A P 3 K 5\end{array}$ \\
\hline Myxoid liposarcoma & $\begin{array}{l}\mathrm{t}(12 ; 16)(\mathrm{q} 13 ; \mathrm{p} 11) \\
\mathrm{t}(12 ; 22)(\mathrm{q} 13 ; \mathrm{q} 12)\end{array}$ & $\begin{array}{l}\text { FUS-DDIT3 } \\
\text { EWSR1-DDIT3 }\end{array}$ \\
\hline Solitary fibrous tumor & $\operatorname{Inv}(12)(q 13 q 13)$ & NAB2-STAT6 fusion \\
\hline Inflammatory myofibroblastic tumor & $\begin{array}{l}\mathrm{t}(1 ; 2)(\mathrm{q} 22 ; \mathrm{p} 23) \\
\mathrm{t}(2 ; 19)(\mathrm{p} 23 ; \mathrm{p} 13) \\
\mathrm{t}(2 ; 17)(\mathrm{p} 23 ; \mathrm{q} 23)\end{array}$ & $\begin{array}{l}\text { TPM3-ALK fusion } \\
\text { TPM4-ALK fusion } \\
\text { CLTC-ALK fusion } \\
\text { ROS1 and PDGFRB rearrangement }\end{array}$ \\
\hline $\begin{array}{l}\text { Epithelioid inflammatory } \\
\text { myofibroblastic sarcoma }\end{array}$ & $\mathrm{t}(2 ; 2)(\mathrm{p} 23 ; \mathrm{q} 13)$ & $R A N B P 2-A L K$ fusion \\
\hline Embryonal rhabdomyosarcoma & $\begin{array}{l}\text { Complex karyotypes; loss of heterozygosity } \\
\text { at } 11 \text { p15.5 }\end{array}$ & \\
\hline Alveolar rhabdomyosarcoma & $\begin{array}{l}\mathrm{t}(2 ; 13)(\mathrm{q} 35 ; \mathrm{q} 14) \\
\mathrm{t}(1 ; 13)(\mathrm{p} 36 ; \mathrm{q} 14)\end{array}$ & $\begin{array}{l}\text { PAX3-FOXO1A fusion } \\
\text { PAX7-FOXO1A fusion }\end{array}$ \\
\hline MPNST & $\begin{array}{l}\text { Complex karyotypes; inactivation } \\
\text { mutations in } N F 1, C D K N 2 A / C D K N 2 B, E E D \text {, } \\
\text { or SUZ12 }\end{array}$ & \\
\hline Epithelioid MPNST & SMARCB1 gene inactivation & \\
\hline Synovial sarcoma & $\mathrm{t}(\mathrm{X} ; 18)(\mathrm{p} 11 ; \mathrm{q} 11)$ & $\begin{array}{l}\text { SS18-SSX1 fusion } \\
\text { SS18-SSX2 fusion }\end{array}$ \\
\hline Desmoplastic small round cell tumor & $\mathrm{t}(11 ; 22)(\mathrm{p} 13 ; \mathrm{q} 12)$ & $\begin{array}{l}\text { EWSR1-WT1, } \\
\text { EWSR1-ERG, EWDR1-FLI1 fusion }\end{array}$ \\
\hline PEComa & Deletion of $16 p$, the location of $T S C 2$ gene & $\begin{array}{l}\text { SFPQ-TFE3, DVL2-TFE3, } \\
\text { NONO-TFE3 fusion }\end{array}$ \\
\hline Extraskeletal Ewing sarcoma & $\begin{array}{l}\mathrm{t}(11 ; 22)(\mathrm{q} 24 ; \mathrm{q} 12) \\
\mathrm{t}(21 ; 22)(\mathrm{q} 12 ; \mathrm{q} 12) \\
\mathrm{t}(2 ; 22)(\mathrm{q} 33 ; \mathrm{q} 12) \\
\mathrm{t}(7 ; 22)(\mathrm{p} 22 ; \mathrm{q} 12) \\
\mathrm{t}(17 ; 22)(\mathrm{q} 12 ; \mathrm{q} 12)\end{array}$ & $\begin{array}{l}\text { EWSR1-FLI1 fusion } \\
\text { EWSR1-ERG fusion } \\
\text { EWSR1-FEV fusion } \\
\text { EWSR1-ETV1 fusion } \\
\text { EWSR1-E1AF fusion }\end{array}$ \\
\hline
\end{tabular}

MPNST, malignant peripheral nerve sheath tumor; PEComa, perivascular epithelioid cell tumor.

In recent years, there has been marked progression in the application of molecular testing to the diagnosis of soft tissue tumors. New development tools such as comparative genomic hybridization, gene expression arrays, and next-generation sequencing make important contributions not only to our biological understanding but also to classification, prognostication, and treatment approaches for soft tissue sarcomas [31]. Interpretation of molecular testing can be sometimes difficult. Paramount is the fact that molecular testing cannot be used in isolation. The selection of any particular molecular testing should be on the basis of a specific differential diagnosis and relevant pretest probabilities [31]. In the setting of unusual histologic and immunohistochemical findings, molecular testing plays a critical role in the differential diagnosis. 


\section{Relatively Common Retroperitoneal Sarcomas}

\subsection{Liposarcoma}

Liposarcoma is a soft tissue sarcoma with lipogenic differentiation and varying biological behavior, ranging from locally aggressive to metastasizing. According to the $2020 \mathrm{WHO}$ classification of soft tissue and bone tumors, liposarcomas are classified into five major subtypes: (1) atypical lipomatous tumor/well-differentiated, (2) dedifferentiated, (3) myxoid, (4) pleomorphic, and (5) myxoid pleomorphic [32]. All liposarcoma subtypes develop in the retroperitoneum. The majority of retroperitoneal liposarcomas are well-differentiated liposarcomas and dedifferentiated subtypes. Pleomorphic and myxoid liposarcomas are rare in the retroperitoneum.

\subsubsection{Well-Differentiated Liposarcoma}

Atypical lipomatous tumor (ALT)/well-differentiated liposarcoma (WDLPS) is a locally aggressive but not metastasizing mesenchymal neoplasm composed either entirely or partly of adipocytic proliferation, showing at least focal nuclear atypia in both adipocytes and stromal cells [33]. ALT/WDLPS accounts for approximately $40-45 \%$ of all liposarcomas. It most frequently occurs in the deep soft tissue of the proximal extremities and trunk. The retroperitoneum is also commonly involved. ALT and WDLPS are synonyms describing lesions that are morphologically and genetically identical. Use of either term is determined principally by tumor location and resectability [33]. Tumors arising in the retroperitoneum are very difficult to resect completely and best classified as WDLPS. Clinically, retroperitoneal lesions are often asymptomatic until the tumor has exceeded $20 \mathrm{~cm}$ in diameter.

Histologically, ALT/WDLPS is divided into three subtypes: (1) adipocytic (lipoma-like), (2) sclerosing, and (3) inflammatory [34]. The presence of more than one morphological pattern in the same lesion is common, particularly in retroperitoneal tumors. Adipocytic (lipoma-like) WDLPS shows mature adipocytes with variation in size along with nuclear hyperchromasia and atypia of the adipocytes and stromal cells. Lipoblasts can also be found. Sclerosing WDLPS shows scattered bizarre stromal cells with nuclear hyperchromasia in an extensively collagenous stroma. Inflammatory WDLPS occurs most often in the retroperitoneum and has dense, chronic inflammatory cell infiltrate with scattered, atypical, often bizarre multinucleated stromal cells (Figure 1) [35]. Immunohistochemically, nuclear expression of MDM2 and CDK4 is present in most cases. FISH evaluation for amplification of MDM2 can help confirm the diagnosis [36].

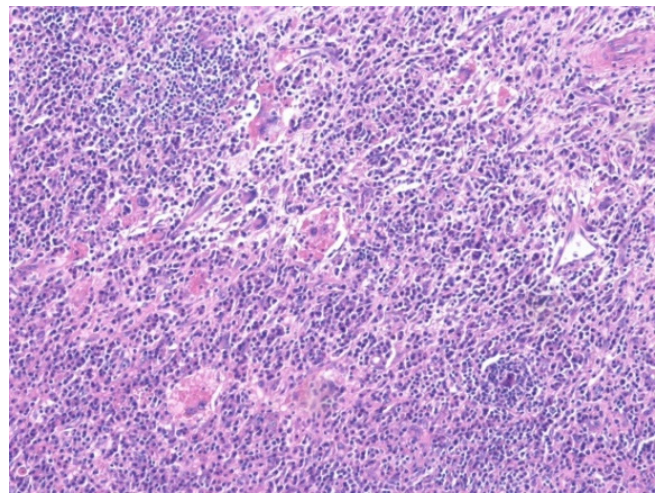

(a)

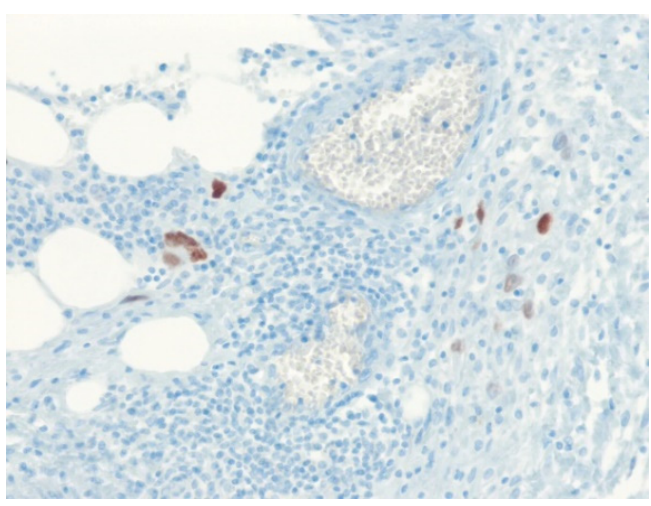

(b)

Figure 1. Well-differentiated liposarcoma, inflammatory subtype. (a) The tumor shows an abundant chronic inflammatory cell infiltrate and scattered atypical pleomorphic stromal cells. (b) The atypical stromal cells are positive for MDM2 (H\&E stain, original magnification 100× a; MDM2 immunostain, original magnification $200 \times$ b). 
Differential diagnoses of WDLPS include retroperitoneal lipoma, atypical spindle cell/pleomorphic lipomatous tumor, lipomatous (fat-forming) solitary fibrous tumor (SFT), and dedifferentiated liposarcoma. Benign lipomas of the retroperitoneum are extremely rare and are circumscribed, multilobulated, and composed of normal-appearing mature adipose tissue, with no cytologic atypia [37]. Diagnosis of retroperitoneal lipoma should be made after very careful histologic, cytogenetic, and molecular analyses. Atypical spindle cell/pleomorphic lipomatous tumors rarely occur in the retroperitoneum and are negative for MDM2 and CDK4 [38]. Lipomatous (fat-forming) SFTs are positive for STAT6 and negative for MDM2 and CDK4 [39]. Dedifferentiated liposarcomas show cellular, usually non-lipogenic sarcomas with a wide morphological spectrum. Inflammatory WDLPS should be distinguished from inflammatory myofibroblastic tumor, Castleman disease, and hematologic malignancy. The presence of MDM2-positive, atypical stromal cells is a useful diagnostic clue.

\subsubsection{Dedifferentiated Liposarcoma}

Dedifferentiated liposarcoma (DDLPS) is an ALT/WDLPS showing progression, either in the primary or in a recurrence, to a (usually non-lipogenic) sarcoma of variable histological grade [40]. A well-differentiated component may not be found. Rarely, the high-grade component may be lipogenic. Approximately $90 \%$ of cases arise de novo, and $10 \%$ develop in recurrences. The most common site of DDLPS is the retroperitoneum. Other locations include the spermatic cord, mediastinum, head, neck, and trunk [41,42]. DDLPS shows significant genetic overlap with ALT/WDLPS, with amplification of MDM2 and CDK4 [43]. Some genomic features appear to be more often related to DDLPS, although not restricted to DDLPS, such as the amplification of JUN (1p32.1), TERT (5p15.33), CPM, MAP3K5, and other genes from the 6q21-q24 region [40]. Clinically, retroperitoneal DDLPSs are frequently found incidentally as large painless masses.

Histologically, DDLPS demonstrates an abrupt or gradual transition from WDLPS to non-lipogenic sarcoma, which, in most cases, is high-grade (Figure 2). Dedifferentiated areas vary histologically but frequently resemble undifferentiated pleomorphic sarcoma or intermediate- to high-grade myxofibrosarcoma [41,44]. Cases with low-grade dedifferentiation are increasing [42]. DDLPSs exhibit heterologous differentiation in around 5-10\% of cases [45]. Most often, the line of heterologous differentiation is rhabdomyosarcomatous, leiomyosarcomatous, or osteosarcomatous. A distinctive neural-like pattern or meningothelial-like whorling pattern is present in some cases [46]. The dedifferentiated component of DDLPS can show homologous lipoblastic differentiation (Figure 3) [47]. WDLPS and DDLPS can show myogenic differentiation [48]. Immunohistochemically, the tumor cells demonstrate nuclear expression of MDM2 and CDK4.

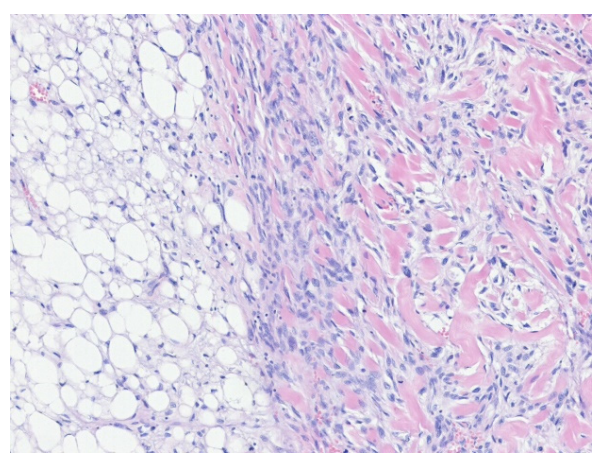

(a)

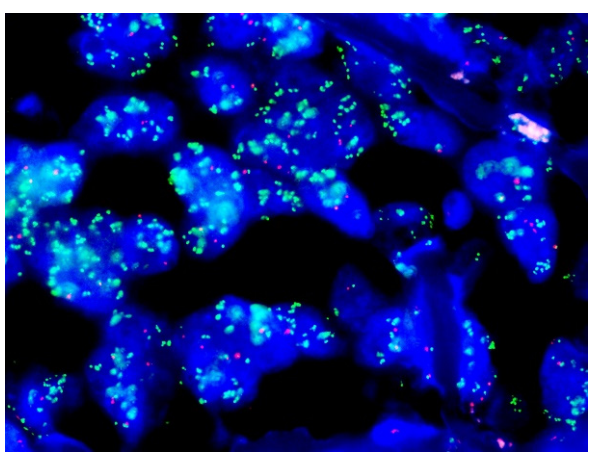

(b)

Figure 2. Dedifferentiated liposarcoma. (a) The tumor shows an abrupt transition from well-differentiated liposarcoma component to a non-lipogenic, high-grade dedifferentiated area (right). (b) The dedifferentiated component shows MDM2 amplification by FISH. The green signal corresponds to the MDM2 probe, while the red signal corresponds to the chromosome 12 centromeric probe (H\&E stain, original magnification $100 \times$ a) MDM2 FISH, original magnification $1000 \times \mathbf{b}$ ). 


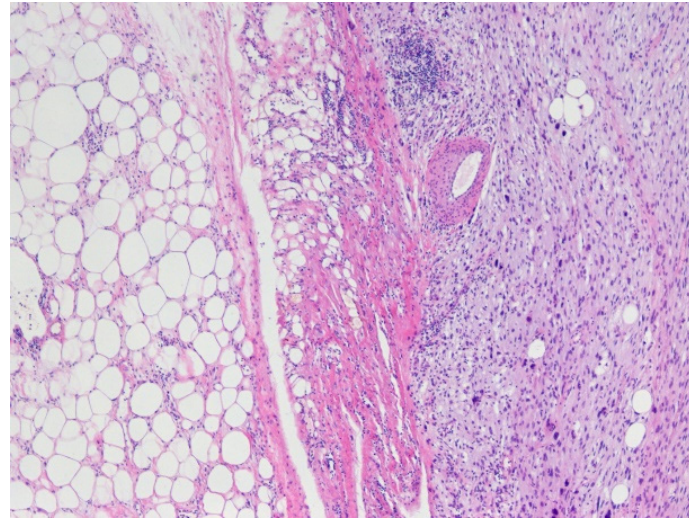

(a)

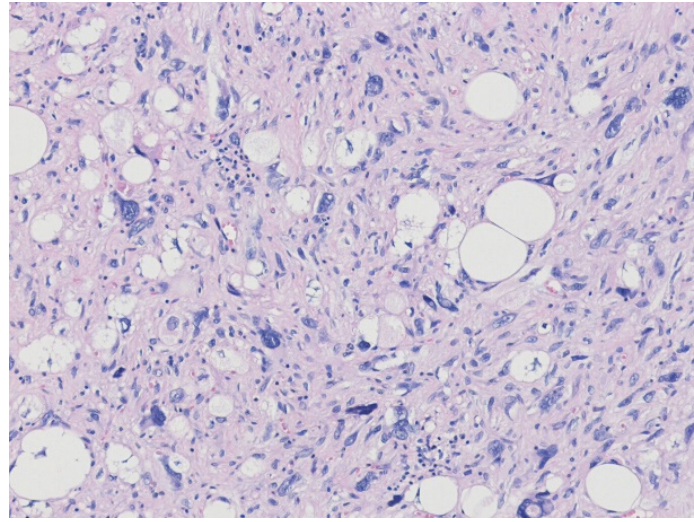

(b)

Figure 3. Dedifferentiated liposarcoma with homologous lipoblastic differentiation. (a) The tumor shows an abrupt transition from well-differentiated liposarcoma component to dedifferentiated component. (b) The dedifferentiated component shows homologous lipoblastic differentiation with scattered lipoblasts. The morphology resembles pleomorphic liposarcoma (H\&E stain, original magnifications $100 \times$ a and $200 \times$ b).

Differential diagnoses of DDLPS are broad as there is morphological heterogeneity and they include WDLPS, pleomorphic liposarcoma, pleomorphic leiomyosarcoma, MPNST, and undifferentiated pleomorphic sarcoma (UPS). WDLPSs lack an overtly non-lipogenic sarcoma area. DDLPSs with homologous lipoblastic differentiation can closely resemble pleomorphic liposarcoma. Pleomorphic liposarcomas lack components of WDLPS and show no MDM2 amplification. Pleomorphic leiomyosarcomas lack components of WDLPS and are positive for SMA and desmin but negative for MDM2 and CDK4. MPNSTs show fascicles of spindle cells with wavy, tapering nuclei. MDM2 expression can be seen in MPNST [49]. High-level MDM2 amplification strongly suggests DDLPS over MPNST. UPSs lack components of WDLPS and show no MDM2 amplification. Most tumors resembling UPSs in the retroperitoneum are DDLPSs [50]. Therefore, extensive sampling with immunohistochemistry for MDM2 and CDK4, and FISH for MDM2 amplification, are helpful to make a proper diagnosis of DDLPS with differential diagnosis.

\subsubsection{Pleomorphic Liposarcoma}

Pleomorphic liposarcoma (PLPS) is a pleomorphic, high-grade sarcoma containing a variable number of pleomorphic lipoblasts [51]. No areas of ALT/WDLPS or other lines of differentiation are present. PLPS is a rare subtype of LPS, accounting for $\sim 5 \%$ of all LPSs. Most cases occur in old adults, with peak incidence in the seventh decade of life. Men are affected slightly more often than women. PLPS most often arises in the lower and upper extremities [52-54]. The retroperitoneum and trunk are less commonly affected. PLPSs share very similar genomic profiles with other high-grade pleomorphic sarcomas and exhibit complex molecular profiles with numerous chromosomal imbalances $[55,56]$. Frequently mutated genes include TP53 (17\% of cases) and NF1 (8\% of cases) [57].

Histologically, PLPS shows a varying proportion of pleomorphic lipoblasts in a background of high-grade, usually pleomorphic undifferentiated sarcoma features. The presence of lipoblasts is necessary for accurate diagnosis of PLPS. Lipoblasts have irregular, hyperchromatic, scalloped nuclei with univacuolated or multivacuolated cytoplasm. Lipoblasts can be few in number and therefore adequate sampling is required to identify them. An intermediate to high-grade myxofibrosarcoma-like component is present in some cases [58]. An epithelioid morphology is seen in around $25 \%$ of cases [59]. Immunohistochemically, S100 protein is positive in adipocytes and may be useful for highlighting lipoblasts in tumors mimicking UPS. Staining for MDM2 and CDK4 is typically negative. Epithelioid variants of PLPS are frequently positive for cytokeratin and melan-A [58]. 
Differential diagnoses of PLPS include WDLPS, DDLPS, myxofibrosarcoma, UPS, and carcinoma. WDLPSs lack pleomorphic lipoblasts and non-lipogenic pleomorphic sarcoma components and are positive for MDM2 and CDK4. DDLPSs frequently contain components of WDLPS and are positive for MDM2 and CDK4 and show MDM2 amplification. Myxofibrosarcomas are extremely rare in the retroperitoneum and lack lipoblastic differentiation. UPSs show no evidence of lipoblastic differentiation and are negative for MDM2 and CDK4. Epithelioid variants of PLPS may be mistaken for poorly differentiated carcinomas, such as adrenal cortical and renal cell carcinoma. Carcinomas are positive for epithelial markers (e.g., cytokeratin, EMA). Recognition of pleomorphic lipoblasts is the most important diagnostic clue for PLPS. Lipoblast-like cells may be seen in a variety of conditions, and failure to recognize an appropriate histologic background can lead to an erroneous diagnosis of LPS [60].

\subsubsection{Myxoid Liposarcoma}

Myxoid liposarcoma (MLPS) is a malignant tumor composed of uniform, round to ovoid cells and a variable number of small lipoblasts [61]. MLPS is set in a myxoid stroma with a branching capillary vasculature and accounts for approximately $20-30 \%$ of LPSs. The peak incidence is in the fourth and fifth decades of life. MLPSs typically develop within the deep soft tissues of the extremities. Distant metastases develop in approximately 30-60\% of cases. Primary retroperitoneal MLPSs are extremely rare [62,63]. Most cases of MLPS in the retroperitoneum represent a metastasis. MLPSs show a specific $\mathrm{t}(12 ; 16)(\mathrm{q} 13 ; \mathrm{p} 11)$ with FUS-DDIT3 fusion gene in most cases (90-95\%) and rarely $\mathrm{t}(12 ; 22)(\mathrm{q} 13 ; \mathrm{q} 12)$ with EWSR1-DDIT3 fusion gene [64]. Clinically, MLPSs present as large, painless masses.

Histologically, MLPS is a moderately cellular, lobulated tumor composed of uniform, small, ovoid cells in a myxoid stroma with variable numbers of small lipoblasts [61]. Increased cellularity is typically present in the periphery of the lobules. A characteristic plexiform, delicately arborizing, capillary network (chicken wire pattern) is present. The transitional area with modest increase in cellularity should not be interpreted as a round cell change. High-grade MLPS ( $>5 \%$ round cell component) shows cellular overlapping, larger and more hyperchromatic nuclei, and increased mitotic activity. High-grade tumors have a higher risk of metastasis or death from the disease $[65,66]$. Immunohistochemically, S100 protein may highlight lipoblasts or show focal expression in round cell areas.

Differential diagnoses of MLPSs include WDLPS, myxofibrosarcoma, poorly differentiated synovial sarcoma, and extraskeletal Ewing sarcoma (ES). WDLPSs show scattered enlarged hyperchromatic stromal cells and are positive for MDM2 and CDK4. In adipocytic tumors with myxoid stroma arising in the retroperitoneum, the possibility of WDLPS should be first considered. Myxofibrosarcomas show nuclear atypia and pleomorphism and lack true lipoblasts, with a curvilinear vascular pattern rather than chicken-wire vascular pattern. High-grade MLPS requires a differential diagnosis from poorly differentiated synovial sarcomas that lack lipoblasts and an arborizing capillary vascular pattern and are diffusely positive for TLE1 and SS18-SSX [67]. Extraskeletal ESs lack lipoblasts and an arborizing capillary vascular pattern and show strong membranous positivity for CD99 and nuclear positivity for NKX2.2.

\subsection{Leiomyosarcoma}

Leiomyosarcoma is a malignant neoplasm composed of cells showing smooth muscle differentiation [68]. Soft tissue leiomyosarcomas commonly arise in the extremities (particularly the lower extremities), retroperitoneum, abdomen, pelvis, and trunk [69,70]. Leiomyosarcoma is the second most common sarcoma in the retroperitoneum. Retroperitoneal leiomyosarcoma usually occurs in middle-aged or older adults, with a female predominance. A subset of retroperitoneal leiomyosarcomas arises from large blood vessels, including the inferior vena cava and renal vein [71]. Retroperitoneal leiomyosarcomas are typically large and often difficult to excise with clear margins.

Histologically, leiomyosarcoma typically shows fascicles of spindle-shaped tumor cells with blunt-ended nuclei and moderate to abundant, brightly eosinophilic fibrillary cytoplasm (Figure 4). Higher-grade tumors exhibit nuclear atypia, frequent mitotic figures, and granular tumor necrosis. 
Histologic variants include inflammatory leiomyosarcoma [72], Epstein-Barr virus-associated smooth muscle tumors [73], myxoid leiomyosarcoma [74], epithelioid leiomyosarcoma [75], pleomorphic leiomyosarcoma [76], and dedifferentiated leiomyosarcoma [77]. Criteria for malignancy in retroperitoneal smooth muscle tumors are still unclear [78]. Mitotic activity, nuclear atypia, and coagulative necrosis are important prognostic factors. Retroperitoneal smooth muscle tumors showing nuclear atypia with any mitosis can be considered as malignancy [79]. Retroperitoneal uterine-type smooth muscle tumors with 5 to 10 mitoses per 50 high-power fields (HPFs) and no other worrisome features can be regarded as having uncertain malignant potential [80]. ER and PR are frequently positive. Immunohistochemically, at least one myogenic marker (i.e., SMA, desmin, or caldesmon) is positive, with $>70 \%$ of cases showing positivity for more than one of these markers. Tumor cells are also positive for cytokeratin and EMA in approximately $40 \%$ of cases [81].

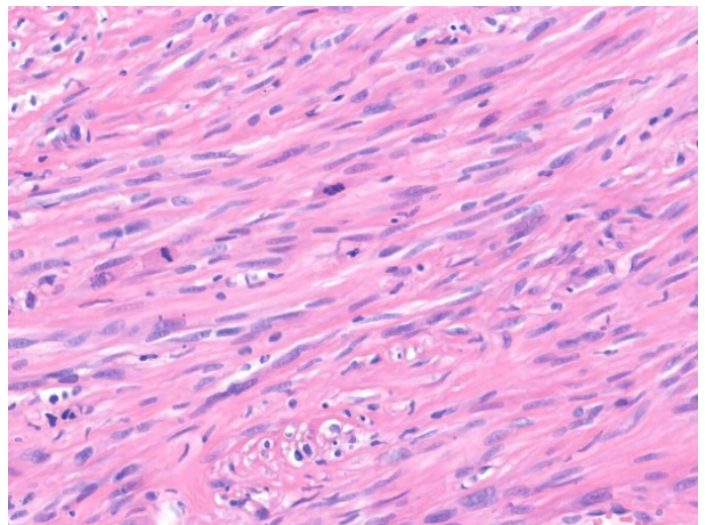

(a)

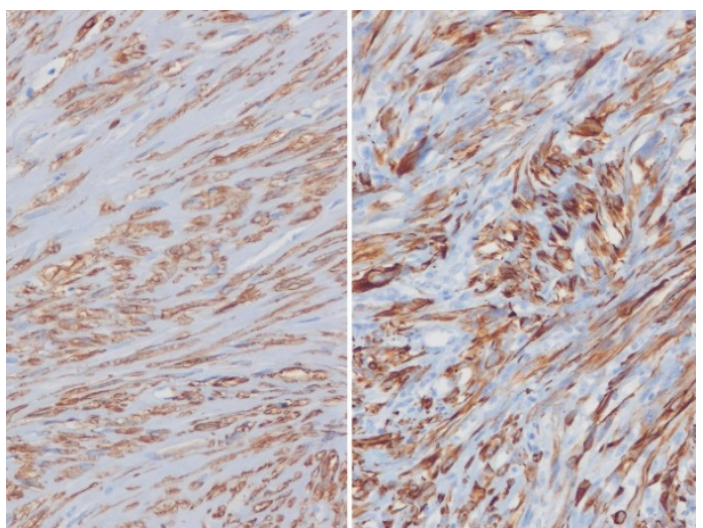

(b)

Figure 4. Leiomyosarcoma. (a) The tumor cells have cigar-shaped, blunt-ended nuclei with brightly eosinophilic cytoplasm and a fascicular pattern. Mitoses are present. (b) The tumor cells are diffusely positive for SMA (left) and desmin (right) (H\&E stain, original magnification $20 \times \mathbf{a}$; SMA and desmin immunostain, original magnification $200 \times$ b).

Differential diagnoses of leiomyosarcoma include schwannoma, inflammatory myofibroblastic tumor (IMT), gastrointestinal stromal tumor (GIST), MPNST, synovial sarcoma, perivascular epithelioid cell tumor (PEComa), and UPS. Schwannomas are strongly and diffusely positive for S100 protein. IMTs show admixed chronic inflammatory cell component and are positive for ALK. GISTs usually arise from the gastrointestinal tract wall, mesentery, or omentum, are occasionally positive for SMA but are diffusely positive for CD34, CD117, and DOG1. MPNSTs are focally positive for S100 protein in $<50 \%$ of cases and show loss of H3K27me3 expression. Synovial sarcomas demonstrate monomorphic tumor cells and are strongly and diffusely positive for TLE1 and SS18-SSX. PEComas show sheets of epithelioid and spindle cells and are positive for melanocytic markers (e.g., HMB-45, melan-A). UPSs lack areas of conventional leiomyosarcoma and are negative for desmin and caldesmon.

\section{Rare Retroperitoneal Sarcomas}

\subsection{Solitary Fibrous Tumor}

Solitary fibrous tumor (SFT) is a fibroblastic tumor characterized by a prominent, branching, thin-walled, dilated (staghorn) vasculature and NAB2-STAT6 gene rearrangement [82]. SFTs may occur at any anatomical site. Extrapleural lesions are more common than pleural lesions. Around $30-40 \%$ of extrapleural SFTs arise in deep soft tissues, including the abdominal cavity, pelvis, and retroperitoneum $[83,84]$. SFTs most commonly affect adults, with a peak incidence between 40 and 70 years. The genetic hallmark of SFT is a paracentric inversion involving chromosome 
12q, resulting in NAB2-STAT6 gene fusion [85]. Clinically, most tumors present as slow-growing, painless masses.

Histologically, SFTs are composed of spindle to ovoid cells with indistinct, pale, eosinophilic cytoplasm that are haphazardly arranged in a collagenous stroma. Branching, staghorn-shaped (hemangiopericytomatous) blood vessels are present. There is a wide histological spectrum. Histologic variants include myxoid SFT [86], lipomatous (fat-forming) SFT [87], giant cell-rich SFT [88], and dedifferentiated SFT (Figure 5) [89]. Malignant SFTs show a high mitotic count ( $>4$ mitoses per $10 \mathrm{HPFs}$ ), increased cellularity, cytological atypia, necrosis, and/or infiltrative growth. Of these features, mitoses are regarded as the most important prognostic factor. A newly described risk stratification model based on patient age, tumor size, mitotic count, and tumor necrosis more clearly delineates prognosis [90].

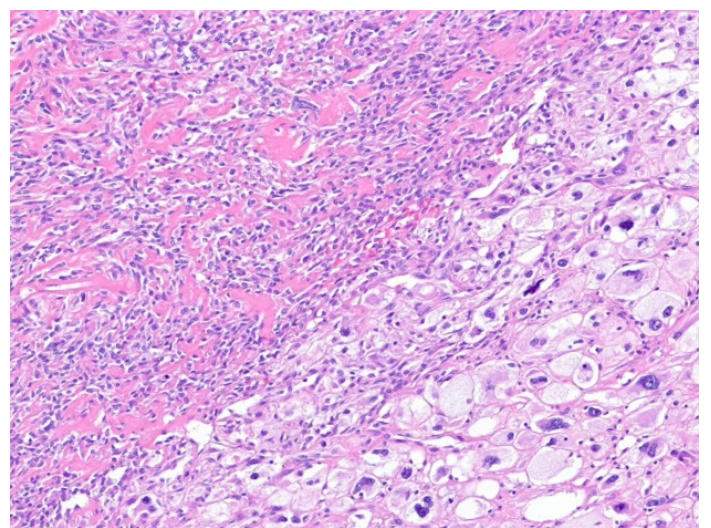

(a)

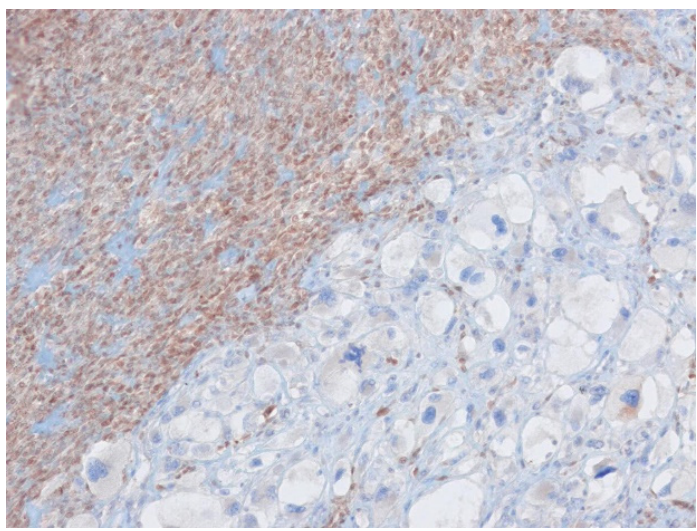

(b)

Figure 5. Dedifferentiated solitary fibrous tumor. (a) The tumor shows an abrupt transition from typical solitary fibrous tumor to high-grade dedifferentiated area. (b) The typical solitary fibrous area shows strong and diffuse positive nuclear expression of STAT6 and the dedifferentiated area shows loss of STAT6 expression (H\&E stain, original magnification 100 $\times$ a; STAT6 immunostain, original magnification $100 \times$ b).

Rhabdomyoblastic differentiation is also described as a rare phenomenon in malignant SFT [91]. Immunohistochemically, the tumor cells exhibit strongly and diffusely positive cytoplasmic expression of CD34 and nuclear STAT6 expression; however, the expression of CD34 and STAT6 is frequently lost in dedifferentiated SFT. STAT6 is a highly sensitive and specific immunohistochemical marker for SFT [92].

Differential diagnoses of SFT include schwannoma, GIST, MPNST, synovial sarcoma, and DDLPS. Schwannomas are strongly and diffusely positive for S100 protein. GISTs are positive for CD117 and DOG1 and negative for STAT6. MPNSTs show wavy, tapering, fascicularly arranged nuclei and are focally positive for S100 protein and SOX 10 in $<50 \%$ and $<70 \%$ of cases, respectively. Synovial sarcomas demonstrate strong and diffuse nuclear expression of TLE1 and SS18-SSX and are negative for CD34 and STAT6. Approximately 10\% of DDLPSs cases express STAT6, which may be a potential pitfall in the differential diagnosis of SFTs, particularly malignant SFTs [93-95]. DDLPSs are positive for MDM2 and CDK4 and show MDM2 amplification.

\subsection{Inflammatory Myofibroblastic Tumor}

Inflammatory myofibroblastic tumor (IMT) is a distinctive, rarely metastasizing neoplasm composed of myofibroblastic and fibroblastic spindle cells accompanied by inflammatory infiltrate of plasma cells, lymphocytes, and/or eosinophils [96]. IMT occurs mainly in children and young adults but can arise in older adults, with a slight female predominance. IMT shows a wide anatomic distribution. It commonly arises in the abdomen (mesentery, omentum) and retroperitoneum [97,98]. In approximately $50-60 \%$ of IMTs, the tumors harbor rearrangement of the $A L K$ gene at chromosome 
2p23. In ALK-negative IMTs, ROS1 gene rearrangement and ETV-NTRK3 gene fusion have been described [99,100]. Approximately $25 \%$ of extrapulmonary IMTs recur. Distant metastases are rare $(<5 \%)$. ALK-negative IMTs exhibit a higher risk of metastasis than ALK-positive IMTs [101]. ALK-negative IMTs also occur in older patients and have greater nuclear pleomorphism, atypia, and atypical mitoses. Clinically, the site of origin determines symptoms.

Histologically, IMT is composed of spindle-shaped fibroblasts and myofibroblasts in a myxoid and collagenous stroma with prominent inflammatory cell infiltrate, including lymphocytes and plasma cells. The three basic histological patterns are (1) myxoid pattern characterized by loosely arranged spindle cells in an edematous myxoid stroma with abundant blood vessels, (2) hypercellular pattern showing compact spindle cell proliferation, and (3) hypocellular fibrous pattern characterized by hyalinized collagenous stroma and relatively sparse inflammatory infiltrate [96,97]. A variety of histologic patterns may be present in the same tumor. Epithelioid inflammatory myofibroblastic sarcoma (EIMS) is a distinctive IMT subtype with plump, round epithelioid or histiocytoid tumor cells (Figure 6) [102]. EIMS is associated with RANBP2-ALK or RRBP1-ALK gene rearrangement and has an aggressive clinical course. Immunohistochemically, IMTs show variable positivity for myofibroblastic markers (e.g., SMA, muscle-specific actin, and desmin). Immunoreactivity for ALK is present in $50-60 \%$ of cases. The ALK immunostaining pattern varies depending on the $A L K$ fusion partner. RANBP2-ALK is associated with a nuclear membranous pattern.

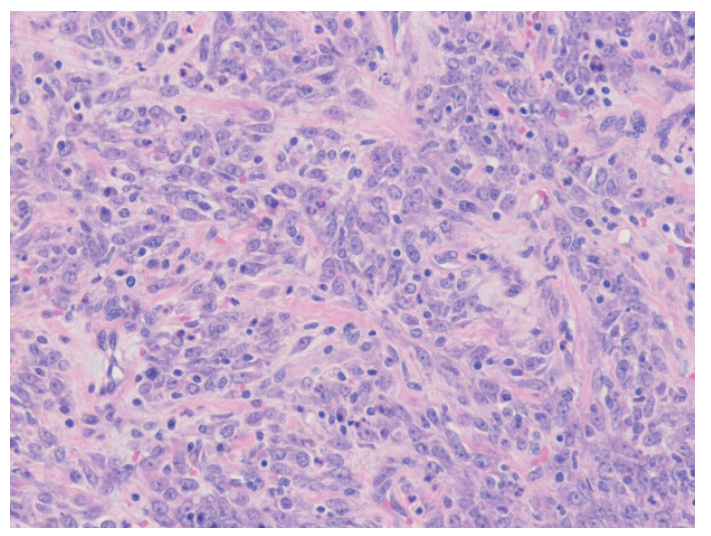

(a)

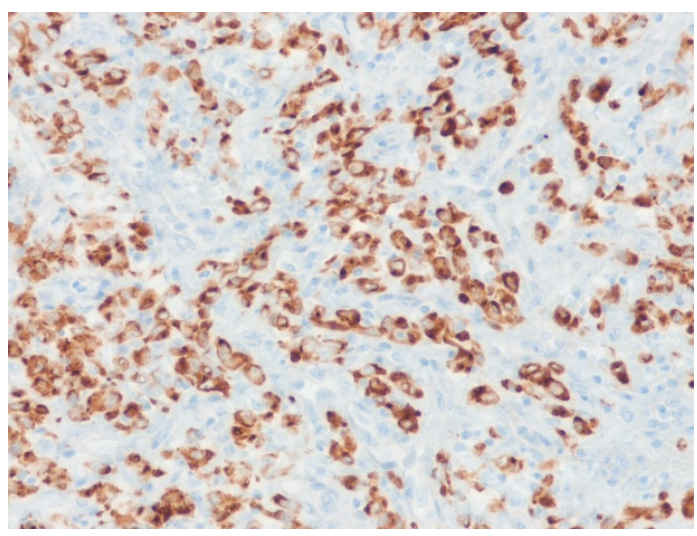

(b)

Figure 6. Epithelioid inflammatory myofibroblastic sarcoma. (a) The tumor cells are round to epithelioid-shaped and have prominent nucleoli, with mild infiltration of inflammatory cells, including neutrophils and lymphocytes. (b) The tumor cells show nuclear membranous staining for ALK (H\&E stain, original magnification $200 \times$ a; ALK immunostain, original magnification $200 \times \mathbf{b}$ ).

Differential diagnoses of IMT vary according to histologic patterns and include retroperitoneal fibrosis, desmoid fibromatosis, GIST, inflammatory WDLPS, DDLPS, and leiomyosarcoma. Retroperitoneal fibrosis is a rare lesion involving soft tissues or organs in the retroperitoneum and can be classified into IgG4-related and non-IgG4-related cases [103]. It shows dense fibrosis with chronic inflammatory cell infiltrate and is negative for ALK. Desmoid fibromatosis exhibits long fascicles of bland spindle cells and nuclear $\beta$-catenin expression. GISTs are diffusely positive for CD117 and DOG1. Inflammatory WDLPSs are positive for MDM2 and CDK4. DDLPSs contain components of WDLPS and are positive for MDM2 and CDK4. Leiomyosarcomas may have a prominent inflammatory cell infiltrate but show conventional leiomyosarcoma morphology and are diffusely positive for SMA and negative for ALK. 


\subsection{Rhabdomyosarcoma}

Rhabdomyosarcoma (RMS) is a malignant soft tissue tumor showing various stages in the embryonic differentiation of skeletal muscle. RMS is the most common soft tissue sarcoma in children and adolescents, with 4.5 cases per million individuals aged 0-20 years. However, it can affect patients of all ages [104]. The 2020 WHO classification of RMS is divided into embryonal, alveolar, pleomorphic, and spindle cell/sclerosing subtypes. RMS is the most common retroperitoneal sarcoma in children. The most common subtype of primary retroperitoneal RMS is embryonal RMS. Alveolar, pleomorphic, and spindle cell/sclerosing RMS subtypes rarely arise in the retroperitoneum [105-107]. Clinically, RMS presents with a variety of clinical symptoms, generally related to the mass effect.

Histologically, embryonal RMS is composed of spindle cells and more primitive rounded cells, variably differentiated round, strap-shaped, or tadpole-shaped eosinophilic rhabdomyoblasts with alternating areas of loose and dense cellularity (Figure 7). Histologic variants of embryonal RMS include the botryoid and anaplastic types [108]. Occasionally, embryonal RMSs show a dense cellular pattern of primitive round cells, simulating alveolar RMSs [109]. Alveolar RMS shows uniform primitive round cell morphology with an alveolar growth pattern [110]. Pleomorphic RMS is composed of sheets of large, atypical cells and frequently multinucleated polygonal, spindle-shaped, or rhabdoid cells [111]. Spindle cell/sclerosing RMS is characterized by cellular spindle cell fascicles or round tumor cells in a sclerotic collagenous stroma [112]. Immunohistochemically, the tumor cells are positive for desmin, myogenin, and MYOD1. Nuclear expression of myogenin is stronger and more uniform in alveolar RMS compared to embryonal RMS. RMSs show diffuse and strong cytoplasmic expression of WT1 [113].

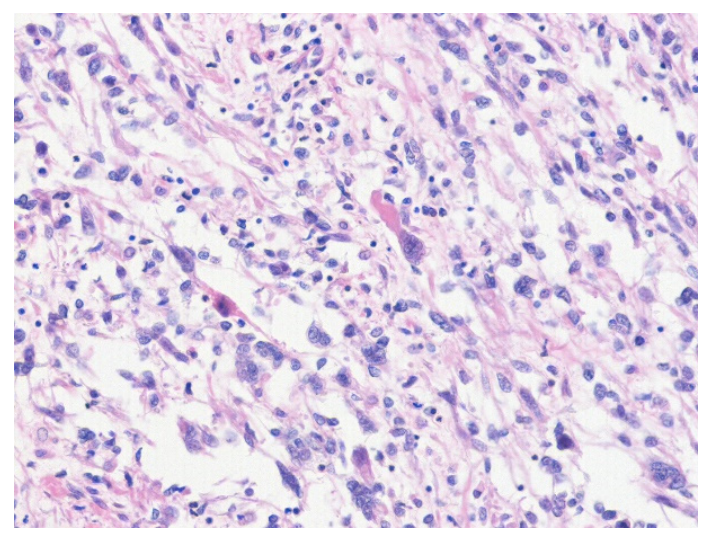

(a)

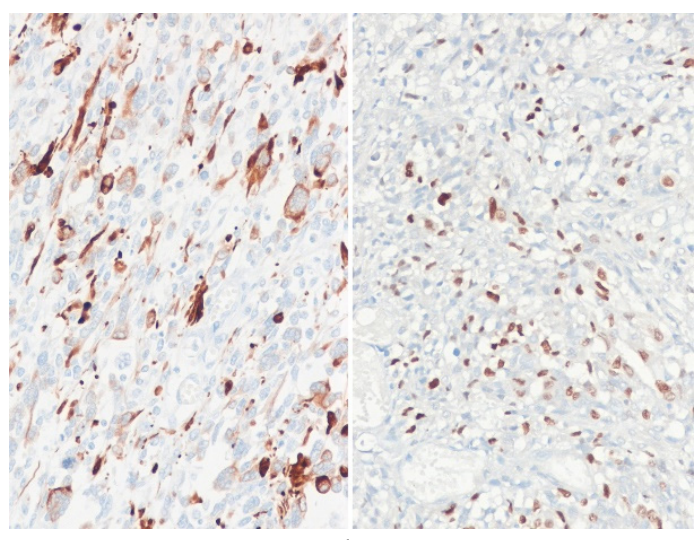

(b)

Figure 7. Embryonal rhabdomyosarcoma. (a) The tumor is composed of primitive round to spindle cells and eosinophilic rhabdomyoblasts. (b) The tumor cells are positive for desmin (left) and myogenin (right) (H\&E stain, original magnification $200 \times \mathbf{a}$; desmin and myogenin immunostain, original magnification $200 \times$ b).

Differential diagnoses of embryonal RMS include infantile fibrosarcoma, alveolar RMS, extraskeletal ES, desmoplastic small round cell tumor (DSRCT), and extrarenal rhabdoid tumor. Infantile fibrosarcomas exhibit intersecting fascicles of primitive ovoid and spindle cells, lack expression of myogenic markers, and show ETV6-NTRK3 gene fusion [114]. Alveolar RMSs show more uniformly rounded, undifferentiated cells with larger nuclei than embryonal RMSs, with an alveolar pattern and diffuse myogenin expression. Extraskeletal ESs show diffuse membrane expression of CD99 and are negative for desmin and myogenin. DSRCTs demonstrate a desmoplastic fibrous stroma and are positive for cytokeratin, EMA, and desmin but negative for myogenin. Extrarenal rhabdoid tumors show polygonal rhabdoid cells with abundant eosinophilic cytoplasm and are positive for cytokeratin and EMA, with loss of SMARCB1 (INI1) expression. 


\subsection{Malignant Peripheral Nerve Sheath Tumor}

Malignant peripheral nerve sheath tumor (MPNST) is a malignant spindle cell tumor that often arises from a peripheral nerve or a pre-existing benign nerve sheath tumor or in a patient with NF1 [115]. MPNST most commonly occurs in patients aged 20-50 years, with a broad age range. Patients with NF1 usually present at a slightly earlier age. MPNST usually arises in the trunk, extremities, head, and neck [116]. Primary retroperitoneal MPNSTs are rare. Patients with NF1 usually develop MPNSTs after a relatively long latency (10-20 years). Approximately 10\% of cases are associated with prior radiation therapy [117]. Rare cases of MPNSTs may arise from schwannoma and ganglioneuroma [118,119]. Clinically, MPNST presents as an enlarging painless or painful mass.

Histologically, MPNST is typically composed of spindle cells with wavy, buckled, tapering nuclei showing a fascicular growth pattern, with alternating hypercellular and hypocellular myxoid areas (Figure 8). A branching hemangiopericytoma-like vascular pattern is often present. Perivascular accentuation of tumor cells may be a diagnostic clue. MPNST has a diverse microscopic appearance. Heterologous differentiation, including rhabdomyoblastic (malignant triton tumor), osteosarcomatous, chondrosarcomatous, and angiosarcomatous, is seen in 10-15\% of MPNSTs [115]. Lipoblastic differentiation is also described as a rare phenomenon in MPNST [120]. Very rare cases may show glandular differentiation (glandular MPNST). Epithelioid MPNST is composed of plump, epithelioid cells with abundant eosinophilic cytoplasm [121]. MPNSTs could show an enhanced level of pleomorphism; in such cases, the differentials include a variety of pleomorphic sarcomas, particularly DDLPS [49]. Recently, the term "atypical neurofibromatous neoplasms of uncertain biologic potential" was proposed for lesions displaying at least two of the following four features in patients with NF1: (1) cytological atypia, (2) loss of neurofibroma architecture, (3) hypercellularity, and (4) mitotic index $>1 / 50$ and $<3 / 10 \mathrm{HPFs}$ [122]. Immunohistochemically, tumor cells are focally positive for S100 protein ( $<50 \%$ of cases), SOX10 ( $<70 \%$ of cases), and GFAP (20-30\% of cases) [108]. Complete loss of H3K27me3 is helpful in the diagnosis of MPNST, with high-grade tumors showing more frequent loss than low-grade tumors [123].

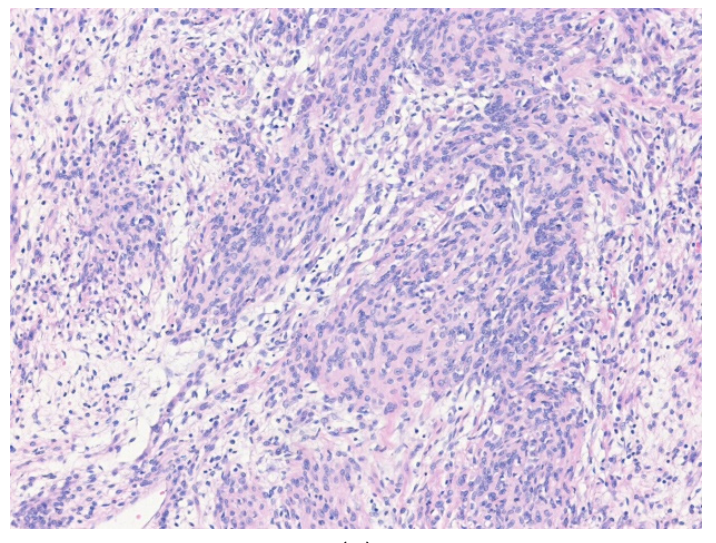

(a)

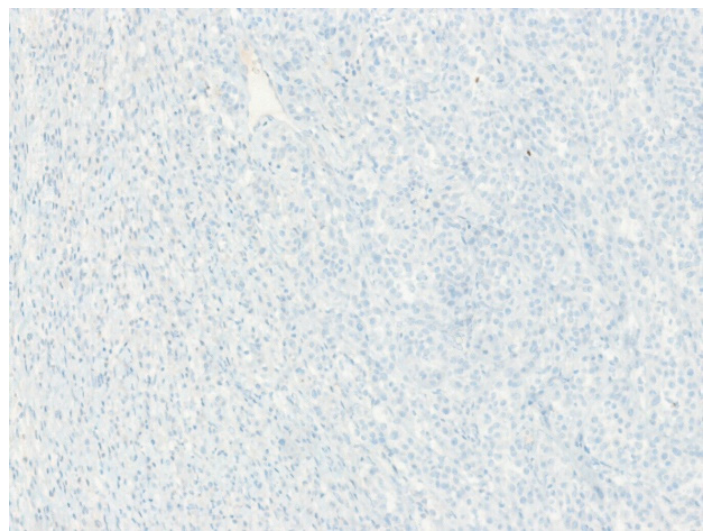

(b)

Figure 8. Malignant peripheral nerve sheath tumor. (a) The tumor is composed of spindle cells with alternating hypercellular and hypocellular areas. (b) The tumor cells show loss of H3K27me3 expression (H\&E stain, original magnification 100× a; H3K27me3 immunostain, original magnification 200× b).

Differential diagnoses of MPNST include schwannoma, DDLPS, leiomyosarcoma, RMS, synovial sarcoma, and malignant melanoma. Schwannomas lack malignant cytologic atypia and are strongly and diffusely positive for S100 protein. DDLPSs show components of WDLPS and are positive for MDM2 and CDK4. Leiomyosarcomas show smooth muscle cytomorphology and are positive for SMA, caldesmon, and desmin. RMSs do not arise in association with a large nerve or within the context of NF1 and show retained (i.e., normal) nuclear staining for H3K27me3 [124]. 
Monophasic synovial sarcomas show more uniform nuclei with wiry stromal collagen and are diffusely positive for TLE1 and SS18-SSX and focally positive for cytokeratin and EMA. Primary or metastatic retroperitoneal malignant melanomas are extremely rare and show spindle and epithelioid cells with severe nuclear atypia and are diffusely positive for S100 protein and other melanocytic markers (e.g., HMB-45, melan-A).

\subsection{Extraskeletal Osteosarcoma}

Extraskeletal osteosarcoma (EOS) is a malignant tumor characterized by production of osteoid or bone matrix by neoplastic cells and arises without connection to the skeletal system [125]. EOS accounts for $<1 \%$ of all soft tissue sarcomas and around $4 \%$ of all osteosarcomas. It usually arises in midlife and late adulthood. The majority of cases develop de novo. Approximately 5-10\% of cases develop at sites of previous irradiation [126]. EOS most commonly occurs in the limbs, especially the thigh, but the anatomic distribution is wide [127]. The retroperitoneum is a frequent site for EOS [128]. Plain radiographs, $\mathrm{CT}$, and MRI usually reveal a large soft tissue mass with variable calcification.

EOS shows a broad spectrum of histologic patterns. All the major types of osteosarcoma that arise in bone are seen in EOS. Depending on the dominant histologic pattern, osteosarcomas are divided into osteoblastic, fibroblastic, chondroblastic, telangiectatic, and small cell types (Figure 9). Osteoblastic type is the most common pattern. Mixed patterns are frequently present. The tumor cells are variably pleomorphic spindle or polygonal cells. Abundant mitotic activity with atypical mitotic figures is present. The presence of neoplastic osteoid (unmineralized matrix) and bone is necessary for diagnosis. Neoplastic bone is intimately associated with malignant tumor cells and varies from thin lace-like, trabeculae to compact bone. Amplification of MDM2 can be detected in some of the high-grade EOSs [129]. Immunohistochemically, SATB2 is sensitive but not specific for osteosarcoma [130,131].

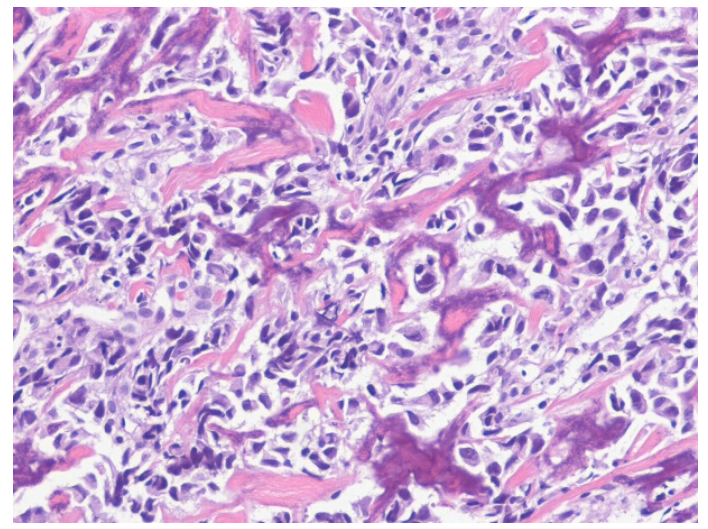

(a)

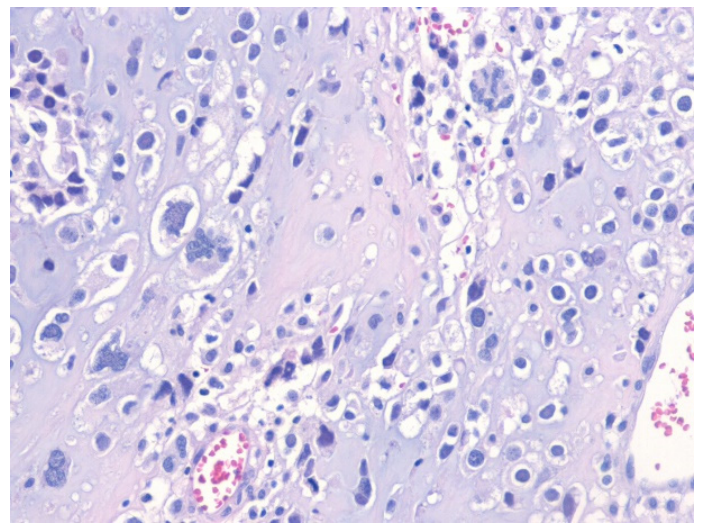

(b)

Figure 9. Extraskeletal osteosarcoma. (a) The tumor consists of hyperchromatic tumor cells producing lace-like neoplastic bone. (b) The tumor shows a cartilaginous area (H\&E stain, original magnification $200 \times \mathbf{a}$ and $200 \times \mathbf{b}$ ).

Differential diagnoses of EOS include benign and malignant bone-forming lesions such as myositis ossificans, DDLPS, MPNST, ossifying synovial sarcoma, and UPS. Myositis ossificans shows zonal distribution with peripheral bone maturation and lacks malignant cytologic atypia [132]. DDLPSs with heterologous osteosarcomatous components should be distinguished from EOS [133]. DDLPSs show components of WDLPS and are positive for MDM2 and CDK4. MPNSTs exhibit hyperchromatic spindle cells in fascicles and are focally positive for S100 protein. Ossifying synovial sarcomas demonstrate uniform spindle tumor cells and are positive for cytokeratin, EMA, and TLE1 and reveal $t(X ; 18)$ with SSX2 involvement [134]. UPSs have significant morphological overlap with EOSs but do not show 
neoplastic bone formation. Careful sampling of the lesions and exclusion of the skeletal origin are required for a correct diagnosis of EOS.

\subsection{Synovial Sarcoma}

Synovial sarcoma is a monomorphic blue spindle cell sarcoma showing variable epithelial differentiation [135]. Synovial sarcoma is characterized by a specific chromosomal translocation $\mathrm{t}(\mathrm{X} ; 18)(\mathrm{p} 11 ; \mathrm{q} 11)$ with SS18-SSX fusion gene. It may occur at any age. More than half of the cases occur in adolescents or young adults [136]. The majority (70\%) of synovial sarcomas arise in the deep soft tissue of the lower and upper extremities, often in juxta-articular locations. It may arise primarily in a wide variety of visceral locations, such as the gastrointestinal tract and kidneys [137,138]. Synovial sarcoma rarely develops in the pelvis and retroperitoneum [139]. Up to one third of synovial sarcomas have radiologically detectable calcification that is occasionally extensive.

Histologically, synovial sarcoma is classified into monophasic (spindle cell), biphasic, and poorly differentiated types. Monophasic type is the most common. Monophasic synovial sarcomas are composed of monomorphic spindle cells with granular chromatin, inconspicuous nucleoli, and poorly defined cytoplasm. Stromal mast cells and a branching, hemangiopericytoma-like vascular pattern are present in a variable amount of collagenous stroma. Biphasic synovial sarcoma has epithelial and spindle cell components in varying proportions. Poorly differentiated synovial sarcoma accounts for approximately $5-10 \%$ of cases and is characterized by increased cellularity, greater nuclear atypia, and high mitotic activity ( $>6$ mitoses $/ \mathrm{mm}^{2}$ or $>10$ mitoses per $10 \mathrm{HPFs}$ of $0.17 \mathrm{~mm}^{2}$ ) (Figure 10) $[135,140]$. Immunohistochemically, spindle tumor cells are focally positive for EMA and cytokeratin. Strong and diffuse nuclear staining for TLE1 is present [141]. Although TLE1 is diagnostically useful, it is not totally specific for synovial sarcoma. Recently, a novel SS18-SSX fusion antibody for the diagnosis of synovial sarcoma was described [67].

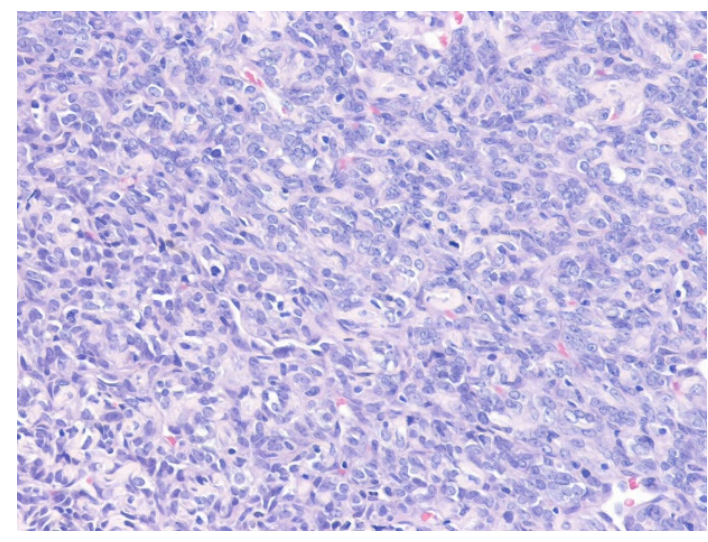

(a)

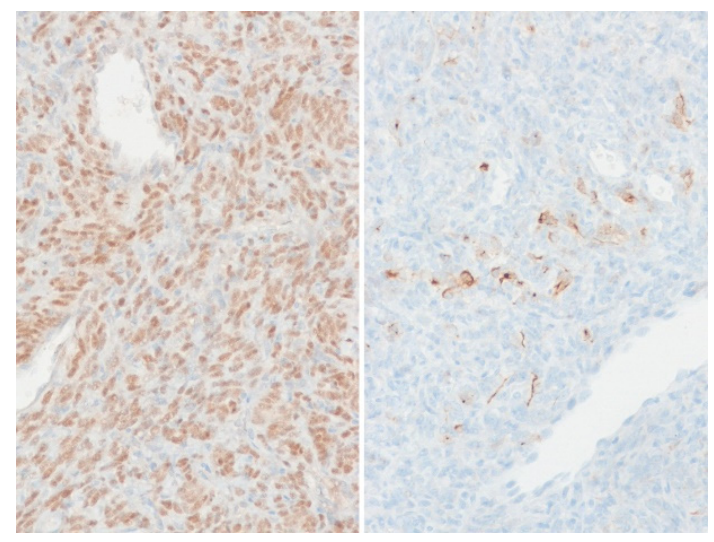

(b)

Figure 10. Poorly differentiated synovial sarcoma. (a) The tumor shows hypercellular rounded tumor cells. Slightly spindled tumor cells are also present. Mitotic figures are frequently seen. (b) The tumor cells are strongly and diffusely positive for TLE1 (left) and focally positive for cytokeratin (AE1/AE3) (right) (H\&E stain, original magnification 200× a; TLE1 and cytokeratin (AE1/AE3) immunostain, original magnification $200 \times$ b) .

Differential diagnoses of synovial sarcoma include SFT, MPNST, leiomyosarcoma, and extraskeletal ES. SFTs show a "patternless pattern", with branching and staghorn vascular patterns, and are diffusely positive for CD34 and STAT6. MPNSTs have wavy, buckled nuclei and are variably positive for S100 protein with loss of H3K27me3 expression. Leiomyosarcomas have blunt-ended, cigar-shaped nuclei, brightly eosinophilic cytoplasm, and are positive for SMA, caldesmon, and desmin. Extraskeletal ESs show diffuse membranous positivity for CD99, nuclear positivity for FLI1, and diffuse nuclear 
expression of NKX2.2. Detection of SS18-SSX fusion transcripts is diagnostic and particularly valuable in synovial sarcomas arising in atypical locations outside the extremities [142].

\subsection{Desmoplastic Small Round Cell Tumor}

Desmoplastic small round cell tumor (DSRCT) is a malignant mesenchymal neoplasm composed of small round tumor cells with polyphenotypic differentiation and prominent stromal desmoplasia [143]. DSRCT was first described by Gerald and Rosai in 1989 [144]. It is characterized by a recurrent chromosomal translocation $\mathrm{t}(11 ; 22)(\mathrm{p} 13 ; \mathrm{q} 12)$, leading to EWSR1-WT1 gene fusion. DSRCT primarily affects children and young adults, with a male predominance. It most commonly arises in the abdominal cavity. It frequently involves any part of the peritoneal cavity and retroperitoneum $[145,146]$. Multiple serosal implants are common. Despite the use of multimodality therapy, it is a highly aggressive neoplasm with extremely poor prognosis [147]. Clinically, patients present with abdominal distention, palpable masses, ascites, and organ obstruction.

Histologically, DSRCT shows nests of small round tumor cells in the desmoplastic stroma. The tumor cells have uniform, small hyperchromatic nuclei, scant cytoplasm, and indistinct cytoplasmic borders (Figure 11). One third of DSRCT cases exhibit a wide range of morphological features. Rhabdoid appearance, epithelial features with gland formation, a large cell variant, spindle-shaped morphology, and rosette formation may be seen $[148,149]$. Desmoplastic stroma is composed of fibroblasts and myofibroblasts in a collagenous matrix. A variably prominent stromal vascularity is present. Immunohistochemically, the tumor cells show a distinct immunophenotype of polyphenotypic differentiation, including expression of epithelial (e.g., cytokeratin, EMA), muscular (e.g., desmin), and neural markers (e.g., NSE, Leu-7). Desmin immunoreactivity for desmin typically appears as a perinuclear dot-like pattern. Nuclear expression of WT1 is present in the vast majority of cases. WT1 immunoreactivity is a useful marker to differentiate DSRCT from other small round cell tumors [150].

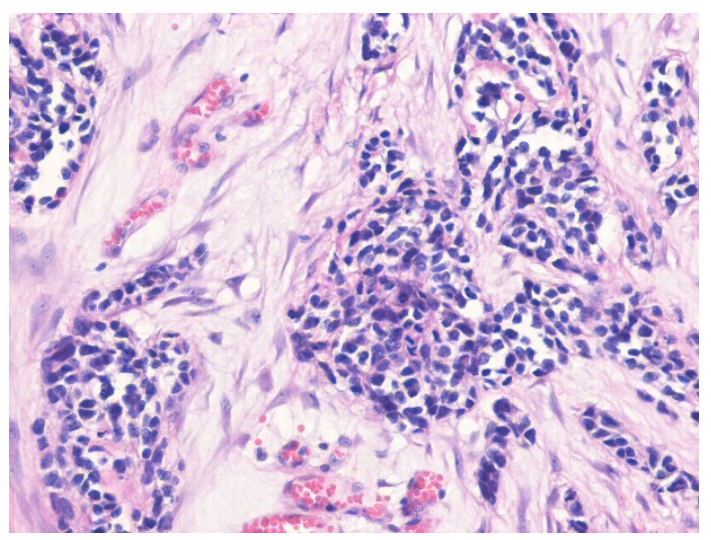

(a)

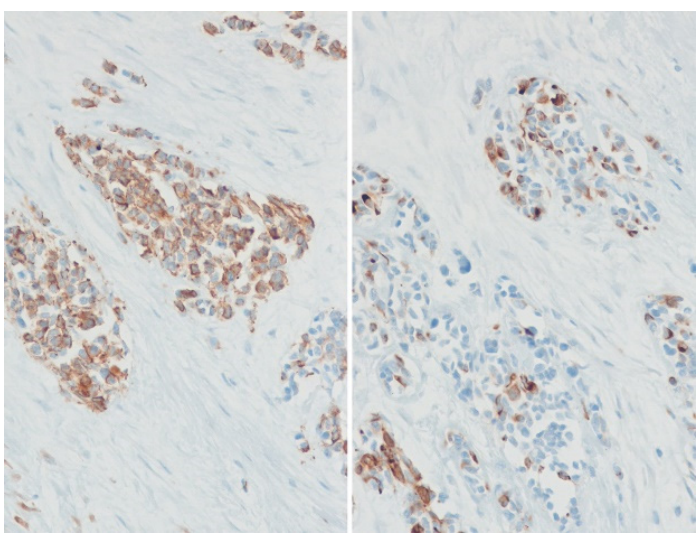

(b)

Figure 11. Desmoplastic small round cell tumor. (a) The tumor shows nests of small round tumor cells within desmoplastic fibrous stroma. (b) The tumor cells are positive for cytokeratin (AE1/AE3) (left) and show perinuclear dot-like expression for desmin (right) (H\&E stain, original magnification 200× a; cytokeratin (AE1/AE3) and desmin immunostain, original magnification $200 \times$ b).

Differential diagnoses of DSRCT include extraskeletal ES, alveolar RMS, extrarenal rhabdoid tumor, neuroblastoma, and metastatic neuroendocrine carcinoma. Extraskeletal ES lacks prominent desmoplastic stroma and shows diffuse membranous positivity for CD99 and nuclear expression of NKX2.2. Alveolar RMSs show nests of central discohesion, with a lack of prominent desmoplastic stroma and positive myogenin and MYOD1 immunoreactivity. Extrarenal rhabdoid tumors show sheets of epithelioid cells and are negative for desmin with loss of nuclear INI1 expression. Neuroblastomas exhibit lobular architecture, an eosinophilic neurofibrillary matrix, a lack of EWSR1 translocation, 
and negative cytokeratin and desmin immunoreactivity. PHOX2B is a sensitive and specific marker for neuroblastoma [151]. Metastatic neuroendocrine carcinomas have a distinctive salt and pepper chromatin pattern and are negative for desmin and WT1.

\subsection{PEComa}

Perivascular epithelioid cell tumors (PEComas) are mesenchymal neoplasms composed of perivascular epithelioid cells (distinctive epithelioid cells that are often closely associated with blood vessel walls) and express both melanocytic and smooth muscle markers [152]. PEComas show a wide anatomical distribution and usually occur in young to middle aged adults, with a marked female predominance. Most often, these tumors arise in the retroperitoneum, abdominopelvic region, gastrointestinal tract, and uterus $[153,154]$. Most PEComas are sporadic; a small subset is associated with tuberous sclerosis complex. Deletion of the TSC2 gene on chromosome 16p and its consequent mTOR activation play a relevant role in the neoplastic process [28]. Clinically, PEComas usually present as a painless mass.

Histologically, PEComa shows epithelioid cells with vesicular nuclei and abundant granular eosinophilic or clear cytoplasm. The tumor cells are arranged in a nested and sheet-like pattern, with surrounding thin-walled, branching blood vessels. Spindle-shaped cells resembling smooth muscle cells and very pleomorphic cells can also be seen. Melanin pigment is occasionally present. Morphological variants include sclerosing PEComa and fibroma-like PEComa [155,156]. Sclerosing PEComas frequently arise in the retroperitoneum and show a densely collagenous stroma (Figure 12). The provisional classification of PEComas into benign, uncertain malignant potential and malignant categories was proposed by Folpe et al. [157]. Lesions with two or more worrisome features (tumor size $>5 \mathrm{~cm}$, infiltrative growth, high nuclear grade, high cellularity, necrosis, mitotic activity $>1$ mitotic figure/50 HPFs, vascular invasion) are classified as malignant PEComa. Immunohistochemically, the tumor cells are positive for melanocytic markers (e.g., HMB-45, melan-A) and smooth muscle markers (e.g., SMA, desmin, caldesmon). TFE3 is positive in a distinct subset of PEComas that harbor TFE3 gene fusions [158].

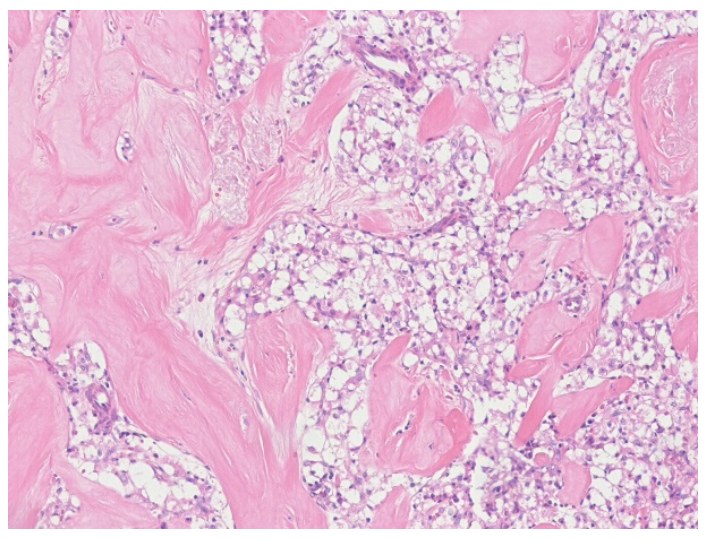

(a)

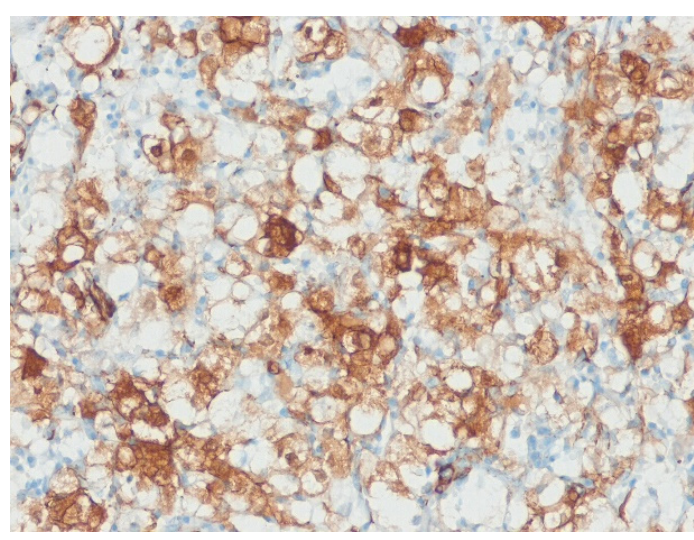

(b)

Figure 12. Sclerosing PEComa. (a) The tumor shows nests of epithelioid tumor cells with abundant clear cytoplasm. The densely hyalinized collagenous stroma is present. (b) The tumor cells are positive for SMA (H\&E stain, original magnification $100 \times$ a; SMA immunostain, original magnification $200 \times \mathbf{b}$ ).

Differential diagnoses of PEComa include GIST, leiomyosarcoma, alveolar soft part sarcoma, malignant melanoma, and metastatic clear cell renal cell carcinoma. GISTs show uniform spindle cells with eosinophilic cytoplasm and indistinct cell borders and are positive for CD34, CD117, and DOG1. Leiomyosarcomas have fascicles of spindle cells with blunt-ended nuclei and brightly eosinophilic cytoplasm. Additionally, they lack a delicate capillary network and are negative for melanocytic markers. Alveolar soft part sarcomas show an alveolar pattern of large eosinophilic or clear epithelioid 
cells and are positive for TFE3 and negative for melanocytic markers. Malignant melanomas show markedly cytologic atypia and are strongly positive for S100 protein and negative for smooth muscle markers. Metastatic clear cell renal cell carcinomas are positive for EMA and PAX8 and negative for melanocytic markers.

\subsection{Undifferentiated Pleomorphic Sarcoma}

Undifferentiated soft tissue sarcoma (USTS) shows no identifiable line of differentiation when analyzed with available technology [159]. At present, it is a heterogeneous group and a diagnosis of exclusion. It accounts for as many as $20 \%$ of all soft tissue sarcomas. USTSs are broadly divided into pleomorphic, spindle cell, round cell, and epithelioid groups [160]. UPS (classified as pleomorphic malignant fibrous histiocytoma in the past) represents the largest group and occurs mostly in older adults. UPSs rarely arise in the retroperitoneum. The etiology of most USTSs is unknown. A subset of cases is radiation-associated [161]. UPSs typically show a nonspecific complex karyotype with numerous genomic rearrangements. Clinically, UPSs have no characteristic clinical features.

Histologically, UPS is composed of highly atypical pleomorphic and/or spindle cells arranged in a storiform, fascicular, or patternless arrangement. Bizarre multinucleated tumor giant cells are frequently present. Abundant mitotic activity, often including atypical forms, is also observed. Pleomorphic soft tissue sarcomas with myogenic differentiation are significantly more aggressive [162,163]. Immunohistochemically, UPSs often show a small number of cells that express SMA, CD34, and cytokeratin. However, these findings are non-specific. Immunohistochemistry and molecular genetics play a major role in excluding other diagnoses.

Differential diagnoses of UPS are broad and include DDLPS, pleomorphic leiomyosarcoma, pleomorphic MPNST, pleomorphic RMS, malignant melanoma, and metastatic sarcomatoid carcinoma. DDLPSs have components of WDLPS and are positive for MDM2 and CDK4 and MDM2 amplification. Most cases of retroperitoneal sarcomas initially diagnosed as so-called malignant fibrous histiocytomas are DDLPS $[50,164]$. Pleomorphic leiomyosarcomas show at least focally eosinophilic spindle cells with blunt-ended nuclei. These cells have a fascicular pattern and are diffusely positive for SMA and variably positive for desmin. In pleomorphic MPNST, the tumor cells are focally positive for S100 protein and SOX10. Complete loss of H3K27me3 is helpful in the diagnosis of MPNST. In pleomorphic RMS, the tumor cells are positive for desmin, myogenin, and MYOD1. Malignant melanomas are positive for S100 protein and melanocytic markers. Metastatic sarcomatoid carcinomas can be excluded by clinical history and are positive for epithelial markers. In cases of pleomorphic malignant neoplasms developing in the retroperitoneum, pathologists should perform extensive sampling combined with appropriate immunohistochemical panels and molecular testing to arrive at a correct diagnosis.

\subsection{Extraskeletal Ewing Sarcoma}

Ewing sarcoma (ES) is a small round cell sarcoma showing gene fusions involving female expressed transcript (FET) family genes (usually EWSR1) and the erythroblast transformation-specific (ETS) family of transcription factors [165]. ES is the second most common sarcoma of the bone in children and young adults, after osteosarcoma. Around 10-20\% of cases are extraskeletal. Extraskeletal ES is most common between the ages of 10 and 30 years. It has a wide anatomical distribution and commonly arises in the extremities (thigh) and trunk (paravertebral region) [166,167]. A variety of visceral locations have been reported [168,169]. Retroperitoneal extraskeletal ESs are rare [170,171]. Although the majority of cases are sporadic, germline mutations have been detected in around $10 \%$ of cases [172].

Histologically, ES is composed of uniform, small round tumor cells. The tumor cells have finely dispersed chromatin with inconspicuous or small nucleoli and scanty, clear, or eosinophilic cytoplasm (Figure 13) [173]. The tumor cells are arranged in a lobular or trabecular pattern. Necrosis is frequently found. Neuroectodermal differentiation (Homer Wright rosettes) may be observed. Rare morphological variants include atypical (large cell) and adamantinoma-like variants [174,175]. Atypical EW consists 
of rather large tumor cells with conspicuous nucleoli and irregular contours. Adamantinoma-like ES shows strong cytokeratin expression or focal keratinization. Immunohistochemically, the tumor cells show a strong and diffuse membranous expression of CD99. Nuclear NKX2.2 expression is more specific for ES than CD99 [176]. Strong nuclear ERG immunoreactivity is specific for ES with EWSR1-ERG rearrangement [177]. Cyclin D1 can be exploitable as a diagnostic adjunct to conventional markers in confirming the diagnosis of ES [178].

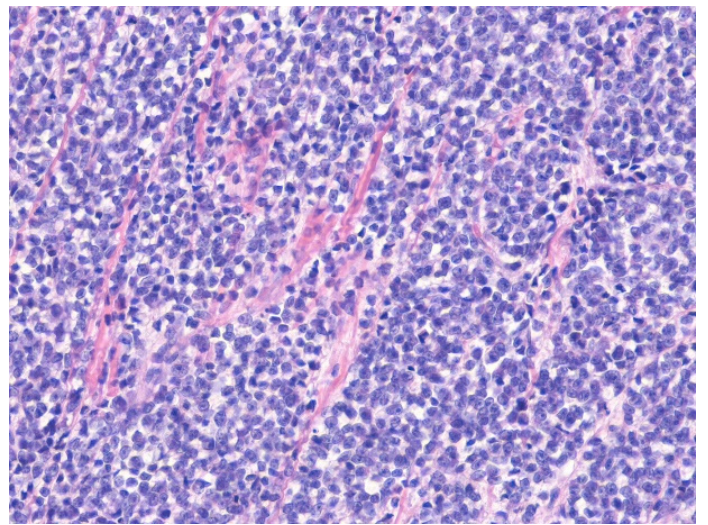

(a)

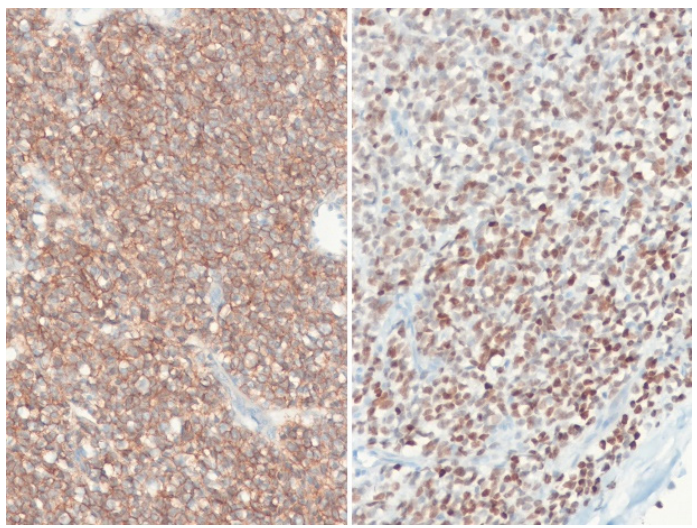

(b)

Figure 13. Extraskeletal Ewing sarcoma. (a) The tumor is composed of uniform small round tumor cells arranged in vaguely lobular pattern. The tumor cells have finely dispersed chromatin and scanty cytoplasm. (b) The tumor cells show diffusely membranous expression for CD99 (left) and diffusely nuclear expression for NKX2.2 (right) (H\&E stain, original magnification 100× a; CD99 and NKX2.2 immunostain, original magnification $100 \times \mathbf{b}$ ).

Differential diagnoses of extraskeletal ES include alveolar RMS, poorly differentiated synovial sarcoma, DSRCT, CIC-rearranged sarcoma, and sarcoma with BCOR genetic alterations. Alveolar RMSs show an alveolar pattern and are positive for desmin and myogenin. Poorly differentiated synovial sarcomas show strong and diffuse positivity for TLE1 and SS18 gene fusions. DSRCTs exhibit a desmoplastic stroma and are positive for cytokeratin, desmin, NSE, and WT1. Recently defined CIC-rearranged sarcomas and sarcomas with BCOR genetic alterations may occur in the retroperitoneum. CIC-rearranged sarcomas show diffuse sheets of undifferentiated small round cells and strong nuclear expression of WT1 and ETV [179]. Sarcomas with BCOR genetic alterations show solid sheets of uniform round to ovoid cells in a myxoid matrix and strong nuclear expression of BCOR and CCNB3 [180].

\section{Miscellaneous Retroperitoneal Mesenchymal Tumors}

Myxofibrosarcoma [181], alveolar soft part sarcoma [182], angiosarcoma [183], clear cell sarcoma of soft tissue [184], and extraskeletal myxoid chondrosarcoma [185] rarely occur in the retroperitoneum. Each of these sarcomas is characterized by distinctive clinicopathologic features and unique genetic findings. Benign mesenchymal tumors, including lipoma [37], leiomyoma [186], schwannoma, and neurofibroma, occur in the retroperitoneum. These tumors may mimic sarcoma. It is important to exclude benign mesenchymal tumors, malignant melanomas, germ cell tumors, malignant lymphomas, parenchymal tumors of retroperitoneal organs (e.g., pancreas, kidneys) located in the retroperitoneal space, and metastatic carcinomas before diagnosing a primary retroperitoneal sarcoma.

\section{Conclusions}

Retroperitoneal sarcomas constitute a rare and diagnostically challenging group of sarcomas that show a wide range of differentiation. Herein, we provide a practical diagnostic approach to retroperitoneal sarcomas and review their histologic features. Adequate sampling for histologic evaluation is necessary. Furthermore, careful integration of clinical history, imaging findings, 
histopathology, immunohistochemistry, and molecular testing is important for correct diagnosis and management. Recent advances in molecular genetic alterations and the emergence of novel diagnostic immunohistochemical markers may further improve diagnostic accuracy for soft tissue tumors.

Funding: This work was supported by the 2019 Yeungnam University Research Grant.

Acknowledgments: The authors thank Pejerrey, Sasha and McConnell, Heather (Houston Methodist Hospital) for their excellent editorial help.

Conflicts of Interest: The authors declare no conflict of interest.

\section{Abbreviations}

\begin{tabular}{ll} 
ALK & anaplastic lymphoma kinase \\
ALT & atypical lipomatous tumor \\
CDK4 & cyclin-dependent kinase 4 \\
CT & computed tomography \\
DDLPS & dedifferentiated liposarcoma \\
DOG1 & discovered on GIST 1 \\
DSRCT & desmoplastic small round cell tumor \\
EMA & epithelial membrane antigen \\
EOS & extraskeletal osteosarcoma \\
ERG & ETS-related gene \\
ES & Ewing sarcoma \\
ETS & erythroblast transformation-specific \\
FET & female expressed transcript \\
FISH & fluorescence in situ hybridization \\
FNCLCC & Fédération nationale des centres de lutte contre le cancer \\
H3K27me3 & histone 3K37 trimethylation \\
H\&E stain & hematoxylin and eosin stain \\
HMB-45 & human melanoma black-45 \\
HPF & high-power field \\
IMT & inflammatory myofibroblastic tumor \\
INI1 & integrase interactor 1 \\
MDM2 & mouse double minute 2 homolog \\
MLPS & myxoid liposarcoma \\
MPNST & malignant peripheral nerve sheath tumor \\
MRI & magnetic resonance imaging \\
MYOD1 & myogenic differentiation 1 \\
NF1 & neurofibromatosis type 1 \\
NKX2.2 & NKX2 homeobox 2 \\
NSE & neuron specific enolase \\
PAX8 & paired box 8 \\
PEComa & perivascular epithelioid cell tumor \\
PLPS & pleomorphic liposarcoma \\
RMS & rhabdomyosarcoma \\
SFT & solitary fibrous tumor \\
SMA & smooth muscle actin \\
TFE3 & transcription factor E3 \\
TLE1 & transducin-like enhancer of split 1 \\
TNM & tumor, lymph node, metastasis \\
UPS & undifferentiated pleomorphic sarcoma \\
WDLPS & well-differentiated liposarcoma \\
WHO & World Health Organization \\
WT1 & Wilms' tumor 1 \\
\hline &
\end{tabular}




\section{References}

1. Fletcher, C.D.M.; Baldini, E.H.; Blay, J.Y.; Gronchi, A.; Lazar, A.J.; Messiou, C.; Pollock, R.E.; Singer, S. Soft tissue tumors: Introduction. In WHO Classification of Tumours. Soft Tissue and Bone Tumours, 5th ed.; The WHO Classification of Tumours Editorial Board, Ed.; IARC Press: Lyon, France, 2020; pp. 1-12.

2. Hornick, J.L. Introduction: Tumor classification and immunohistochemistry. In Practical Soft Tissue Pathology: A Diagnostic Approach, 2nd ed.; Hornick, J.L., Ed.; Elsevier: Philadelphia, PA, USA, 2019; pp. 1-6.

3. The WHO Classification of Tumours Editorial Board. WHO Classification of Tumours. Soft Tissue and Bone Tumours, 5th ed.; IARC Press: Lyon, France, 2020.

4. Van Roggen, J.F.; Hogendoorn, P.C. Soft tissue tumours of the retroperitoneum. Sarcoma 2000, 4, 17-26. [CrossRef] [PubMed]

5. Rosai, J. Rosai and Ackerman's Surgical Pathology, 10th ed.; Elsevier: Philadelphia, PA, USA, 2011; pp. $2251-2258$.

6. Pollock, R.E.; Maki, R.G.; Baldini, E.H.; Hornick, J.L.; Keedy, V.L.; Lazar, A.J.; Madewell, J.E.; Raut, C.P.; Tedder, P.S.; Yoon, S.S. Soft tissue sarcoma of the retroperitoneum. In AJCC Caner Staging Manual, 8th ed.; Amin, M.B., Ed.; American Joint Committee on Cancer, Springer: Chicago, IL, USA, 2017; pp. 531-537.

7. Cormier, J.N.; Pollock, R.E. Soft tissue sarcomas. CA. Cancer J. Clin. 2004, 54, 94-109. [CrossRef] [PubMed]

8. Turnage, R.H.; Mizell, J.; Badgwell, B. Abdominal wall, umbilicus, peritoneum, mesenteries, omentum, and retroperitoneum. In Sabiston Textbook of Surgery: The Biological Basis of Modern Surgical Practice, 20th ed.; Townsend, C.M., Jr., Daniel Beauchamp, R., Mark Evers, B., Mattox, K.L., Eds.; Elsevier: Philadelphia, PA, USA, 2017; pp. 1066-1089.

9. Mito, J.K.; Mitra, D.; Doyle, L.A. Radiation-associated sarcomas: An update on clinical, histologic, and molecular features. Surg. Pathol. Clin. 2019, 12, 139-148. [CrossRef] [PubMed]

10. Widemann, B.C. Current status of sporadic and neurofibromatosis type 1-associated malignant peripheral nerve sheath tumors. Curr. Oncol. Rep. 2009, 11, 322-328. [CrossRef]

11. Levy, A.D.; Manning, M.A.; Al-Refaie, W.B.; Miettinen, M.M. Soft-tissue sarcomas of the abdomen and pelvis: Radiologic-pathologic features, part 1-Common sarcomas: From the radiologic pathology archives. Radiographics 2017, 37, 462-483. [CrossRef]

12. Rajiah, P.; Sinha, R.; Cuevas, C.; Dubinsky, T.J.; Bush, W.H., Jr.; Kolokythas, O. Imaging of uncommon retroperitoneal masses. Radiographics 2011, 31, 949-976. [CrossRef]

13. Thway, K.; Jordan, S.; Fisher, C.; Nicholson, A.G. Updates in the approach to intrathoracic sarcomas. Histopathology 2015, 67, 755-770. [CrossRef]

14. Westra, W.H.; Hruban, R.H.; Phelps, T.H.; Isacson, C. Surgical Pathology Dissection: An Illustrated Guide, 2nd ed.; Springer: New York, NY, USA, 2003; pp. 120-123.

15. Hornick, J.L. Subclassification of pleomorphic sarcomas: How and why should we care? Ann. Diagn. Pathol. 2018, 37, 118-124. [CrossRef]

16. Goldblum, J.R.; Folpe, A.L.; Weiss, S.W. Approach to the diagnosis of soft tissue tumors. In Enzinger and Weiss's Soft Tissue Tumors, 7th ed.; Elsevier: Philadelphia, PA, USA, 2020; pp. 121-128.

17. Samaratunga, H.; Delahunt, B.; Srigley, J.R.; Berney, D.M.; Cheng, L.; Evans, A.; Furusato, B.; Leite, K.R.M.; MacLennan, G.T.; Martignoni, G.; et al. Granular necrosis: A distinctive form of cell death in malignant tumours. Pathology 2020. [CrossRef]

18. Trojani, M.; Contesso, G.; Coindre, J.M.; Rouesse, J.; Bui, N.B.; de Mascarel, A.; Goussot, J.F.; David, M.; Bonichon, F.; Lagarde, C. Soft-tissue sarcomas of adults; study of pathological prognostic variables and definition of histopathological grading system. Int. J. Cancer 1984, 33, 37-42. [CrossRef]

19. Hornick, J.L. Novel uses of immunohistochemistry in the diagnosis and classification of soft tissue tumors. Mod. Pathol. 2014, 27 (Suppl. 1), S47-S63. [CrossRef]

20. Schaefer, I.M.; Fletcher, C.D.M. Recent advances in the diagnosis of soft tissue tumours. Pathology 2018, 50, 37-48. [CrossRef]

21. Borden, E.C.; Baker, L.H.; Bell, R.S.; Bramwell, V.; Demetri, G.D.; Eisenberg, B.L.; Fletcher, C.D.; Fletcher, J.A.; Ladanyi, M.; Meltzer, P.; et al. Soft tissue sarcomas of adults: State of the translational science. Clin. Cancer Res. 2003, 9, 1941-1956.

22. Lahat, G.; Lazar, A.; Lev, D. Sarcoma epidemiology and etiology: Potential environmental and genetic factors. Surg. Clin. North. Am. 2008, 88, 451-481. [CrossRef] [PubMed] 
23. Bridge, J.A. The role of cytogenetics and molecular diagnostics in the diagnosis of soft-tissue tumors. Mod. Pathol. 2014, 27 (Suppl. 1), S80-S97. [CrossRef] [PubMed]

24. Shern, J.F.; Yohe, M.E.; Khan, J. Pediatric rhabdomyosarcoma. Crit. Rev. Oncog. 2015, 20, 227-243. [CrossRef] [PubMed]

25. Lee, W.; Teckie, S.; Wiesner, T.; Ran, L.; Prieto Granada, C.N.; Lin, M.; Zhu, S.; Cao, Z.; Liang, Y.; Sboner, A.; et al. PRC2 is recurrently inactivated through EED or SUZ12 loss in malignant peripheral nerve sheath tumors. Nat. Genet. 2014, 46, 1227-1232. [CrossRef] [PubMed]

26. Schaefer, I.M.; Dong, F.; Garcia, E.P.; Fletcher, C.D.M.; Jo, V.Y. Recurrent SMARCB1 inactivation in epithelioid malignant peripheral nerve sheath tumors. Am. J. Surg. Pathol. 2019, 43, 835-843. [CrossRef]

27. Sawyer, J.R.; Tryka, A.F.; Lewis, J.M. A novel reciprocal chromosome translocation $\mathrm{t}(11 ; 22)(\mathrm{p} 13 ; \mathrm{q} 12)$ in an intraabdominal desmoplastic small round-cell tumor. Am. J. Surg. Pathol. 1992, 16, 411-416. [CrossRef]

28. Pan, C.C.; Chung, M.Y.; Ng, K.F.; Liu, C.Y.; Wang, J.S.; Chai, C.Y.; Huang, S.H.; Chen, P.C.; Ho, D.M. Constant allelic alteration on chromosome 16p (TSC2 gene) in perivascular epithelioid cell tumour (PEComa): Genetic evidence for the relationship of PEComa with angiomyolipoma. J. Pathol. 2008, 214, 387-393. [CrossRef]

29. Rao, Q.; Shen, Q.; Xia, Q.Y.; Wang, Z.Y.; Liu, B.; Shi, S.S.; Shi, Q.L.; Yin, H.L.; Wu, B.; Ye, S.B.; et al. PSF/SFPQ is a very common gene fusion partner in TFE3 rearrangement-associated perivascular epithelioid cell tumors (PEComas) and melanotic Xp11 translocation renal cancers: Clinicopathologic, immunohistochemical, and molecular characteristics suggesting classification as a distinct entity. Am. J. Surg. Pathol. 2015, 39, 1181-1196. [CrossRef] [PubMed]

30. Argani, P.; Zhong, M.; Reuter, V.E.; Fallon, J.T.; Epstein, J.I.; Netto, G.J.; Antonescu, C.R. TFE3-fusion variant analysis defines specific clinicopathologic associations among Xp11 translocation cancers. Am. J. Surg. Pathol. 2016, 40, 723-737. [CrossRef]

31. Wang, W.L.; Lazar, A.J. Applications of molecular testing to differential diagnosis. In Practical Soft Tissue Pathology: A Diagnostic Approach, 2nd ed.; Hornick, J.L., Ed.; Elsevier: Philadelphia, PA, USA, 2019; pp. 513-551.

32. Alaggio, R.; Creytens, D. Myxoid pleomorphic liposarcoma. In WHO Classification of Tumours. Soft Tissue and Bone Tumours, 5th ed.; The WHO Classification of Tumours Editorial Board, Ed.; IARC Press: Lyon, France, 2020; pp. 34-35.

33. Sbaraglia, M.; Dei Tos, A.P.; Pedeutour, F. Atypical lipomatous tumour/well-differentiated liposarcoma. In WHO Classification of Tumours. Soft Tissue and Bone Tumours, 5th ed.; The WHO Classification of Tumours Editorial Board, Ed.; IARC Press: Lyon, France, 2020; pp. 36-38.

34. Evans, H.L. Atypical lipomatous tumor, its variants, and its combined forms: A study of 61 cases, with a minimum follow-up of 10 years. Am. J. Surg. Pathol. 2007, 31, 1-14. [CrossRef] [PubMed]

35. Kraus, M.D.; Guillou, L.; Fletcher, C.D. Well-differentiated inflammatory liposarcoma: An uncommon and easily overlooked variant of a common sarcoma. Am. J. Surg. Pathol. 1997, 21, 518-527. [CrossRef]

36. Clay, M.R.; Martinez, A.P.; Weiss, S.W.; Edgar, M.A. MDM2 and CDK4 immunohistochemistry: Should it be used in problematic differentiated lipomatous tumors? A new perspective. Am. J. Surg. Pathol. 2016, 40, 1647-1652. [CrossRef]

37. Macarenco, R.S.; Erickson-Johnson, M.; Wang, X.; Folpe, A.A.; Rubin, B.P.; Nascimento, A.G.; Oliveira, A.M. Retroperitoneal lipomatous tumors without cytologic atypia: Are they lipomas? A clinicopathologic and molecular study of 19 cases. Am. J. Surg. Pathol. 2009, 33, 1470-1476. [CrossRef] [PubMed]

38. Creytens, D.; Marino-Enriquez, A. Atypical spindle cell/pleomorphic lipomatous tumour. In WHO Classification of Tumours. Soft Tissue and Bone Tumours, 5th ed.; The WHO Classification of Tumours Editorial Board, Ed.; IARC Press: Lyon, France, 2020; pp. 34-35.

39. Creytens, D.; Ferdinande, L. Diagnostic utility of STAT6 Immunohistochemistry in the diagnosis of fat-forming solitary fibrous tumors. Appl. Immunohistochem. Mol. Morphol. 2016, 24, e12-e13. [CrossRef] [PubMed]

40. Dei Tos, A.P.; Marino-Enriquez, A.; Pedeutour, F. Dedifferentiated liposarcoma. In WHO Classification of Tumours. Soft Tissue and Bone Tumours, 5th ed.; The WHO Classification Of Tumours Editorial Board, Ed.; IARC Press: Lyon, France, 2020; pp. 39-41.

41. McCormick, D.; Mentzel, T.; Beham, A.; Fletcher, C.D. Dedifferentiated liposarcoma. Clinicopathologic analysis of 32 cases suggesting a better prognostic subgroup among pleomorphic sarcomas. Am. J. Surg. Pathol. 1994, 18, 1213-1223. [CrossRef] [PubMed] 
42. Henricks, W.H.; Chu, Y.C.; Goldblum, J.R.; Weiss, S.W. Dedifferentiated liposarcoma: A clinicopathological analysis of 155 cases with a proposal for an expanded definition of dedifferentiation. Am. J. Surg. Pathol. 1997, 21, 271-281. [CrossRef]

43. Italiano, A.; Bianchini, L.; Gjernes, E.; Keslair, F.; Ranchere-Vince, D.; Dumollard, J.M.; Haudebourg, J.; Leroux, A.; Mainguené, C.; Mainguené, C.; et al. Clinical and biological significance of CDK4 amplification in well-differentiated and dedifferentiated liposarcomas. Clin. Cancer Res. 2009, 15, 5696-5703. [CrossRef]

44. Weiss, S.W.; Rao, V.K. Well-differentiated liposarcoma (atypical lipoma) of deep soft tissue of the extremities, retroperitoneum, and miscellaneous sites. A follow-up study of 92 cases with analysis of the incidence of "dedifferentiation". Am. J. Surg. Pathol. 1992, 16, 1051-1058. [CrossRef] [PubMed]

45. Evans, H.L.; Khurana, K.K.; Kemp, B.L.; Ayala, A.G. Heterologous elements in the dedifferentiated component of dedifferentiated liposarcoma. Am. J. Surg. Pathol. 1994, 18, 1150-1157. [CrossRef] [PubMed]

46. Nascimento, A.G.; Kurtin, P.J.; Guillou, L.; Fletcher, C.D. Dedifferentiated liposarcoma: A report of nine cases with a peculiar neurallike whorling pattern associated with metaplastic bone formation. Am. J. Surg. Pathol. 1998, 22, 945-955. [CrossRef] [PubMed]

47. Mariño-Enríquez, A.; Fletcher, C.D.; Dal Cin, P.; Hornick, J.L. Dedifferentiated liposarcoma with "homologous” lipoblastic (pleomorphic liposarcoma-like) differentiation: Clinicopathologic and molecular analysis of a series suggesting revised diagnostic criteria. Am. J. Surg. Pathol. 2010, 34, 1122-1131. [CrossRef] [PubMed]

48. Gronchi, A.; Collini, P.; Miceli, R.; Valeri, B.; Renne, S.L.; Dagrada, G.; Fiore, M.; Sanfilippo, R.; Barisella, M.; Colombo, C.; et al. Myogenic differentiation and histologic grading are major prognostic determinants in retroperitoneal liposarcoma. Am. J. Surg. Pathol. 2015, 39, 383-393. [CrossRef] [PubMed]

49. Makise, N.; Sekimizu, M.; Kubo, T.; Wakai, S.; Hiraoka, N.; Komiyama, M.; Fukayama, M.; Kawai, A.; Ichikawa, H.; Yoshida, A. Clarifying the distinction between malignant peripheral nerve sheath tumor and dedifferentiated liposarcoma: A critical appraisal of the diagnostic utility of MDM and H3K27me3 status. Am. J. Surg. Pathol. 2018, 42, 656-664. [CrossRef] [PubMed]

50. Coindre, J.M.; Mariani, O.; Chibon, F.; Mairal, A.; De Saint Aubain Somerhausen, N.; Favre-Guillevin, E.; Bui, N.B.; Stoeckle, E.; Hostein, I.; Aurias, A. Most malignant fibrous histiocytomas developed in the retroperitoneum are dedifferentiated liposarcomas: A review of 25 cases initially diagnosed as malignant fibrous histiocytoma. Mod. Pathol. 2003, 16, 256-262. [CrossRef] [PubMed]

51. Pedeutour, F.; Montgomery, E.A. Pleomorphic liposarcoma. In WHO Classification of Tumours. Soft Tissue and Bone Tumours, 5th ed.; The WHO Classification of Tumours Editorial Board, Ed.; IARC Press: Lyon, France, 2020; pp. 45-46.

52. Downes, K.A.; Goldblum, J.R.; Montgomery, E.A.; Fisher, C. Pleomorphic liposarcoma: A clinicopathologic analysis of 19 cases. Mod. Pathol. 2001, 14, 179-184. [CrossRef]

53. Hornick, J.L.; Bosenberg, M.W.; Mentzel, T.; McMenamin, M.E.; Oliveira, A.M.; Fletcher, C.D. Pleomorphic liposarcoma: Clinicopathologic analysis of 57 cases. Am. J. Surg. Pathol. 2004, 28, 1257-1267. [CrossRef]

54. Gebhard, S.; Coindre, J.M.; Michels, J.J.; Terrier, P.; Bertrand, G.; Trassard, M.; Taylor, S.; Château, M.C.; Marquès, B.; Picot, V.; et al. Pleomorphic liposarcoma: Clinicopathologic, immunohistochemical, and follow-up analysis of 63 cases: A study from the French Federation of Cancer Centers Sarcoma Group. Am. J. Surg. Pathol. 2002, 26, 601-616. [CrossRef]

55. Fritz, B.; Schubert, F.; Wrobel, G.; Schwaenen, C.; Wessendorf, S.; Nessling, M.; Korz, C.; Rieker, R.J.; Montgomery, K.; Kucherlapati, R. Microarray-based copy number and expression profiling in dedifferentiated and pleomorphic liposarcoma. Cancer Res. 2002, 62, 2993-2998. [PubMed]

56. Idbaih, A.; Coindre, J.M.; Derré, J.; Mariani, O.; Terrier, P.; Ranchère, D.; Mairal, A.; Aurias, A. Myxoid malignant fibrous histiocytoma and pleomorphic liposarcoma share very similar genomic imbalances. Lab. Investig. 2005, 85, 176-181. [CrossRef] [PubMed]

57. Barretina, J.; Taylor, B.S.; Banerji, S.; Ramos, A.H.; Lagos-Quintana, M.; Decarolis, P.L.; Shah, K.; Socci, N.D.; Weir, B.A.; Ho, A.; et al. Subtype-specific genomic alterations define new targets for soft-tissue sarcoma therapy. Nat. Genet. 2010, 42, 715-721. [CrossRef] [PubMed]

58. Anderson, W.J.; Jo, V.Y. Pleomorphic liposarcoma: Updates and current differential diagnosis. Semin. Diagn. Pathol. 2019, 36, 122-128. [CrossRef] [PubMed]

59. Huang, H.Y.; Antonescu, C.R. Epithelioid variant of pleomorphic liposarcoma: A comparative immunohistochemical and ultrastructural analysis of six cases with emphasis on overlapping features with epithelial malignancies. Ultrastruct. Pathol. 2002, 26, 299-308. [CrossRef] 
60. Goldblum, J.R.; Folpe, A.L.; Weiss, S.W. Liposarcoma. In Enzinger and Weiss's Soft Tissue Tumors, 7th ed.; Elsevier: Philadelphia, PA, USA, 2020; pp. 520-522.

61. Thway, K.; Nielsen, T.O. Myxoid liposarcoma. In WHO Classification of Tumours. Soft TISSUE and Bone Tumours, 5th ed.; The WHO Classification of Tumours Editorial Board, Ed.; IARC Press: Lyon, France, 2020; pp. 42-44.

62. De Vreeze, R.S.; de Jong, D.; Tielen, I.H.; Ruijter, H.J.; Nederlof, P.M.; Haas, R.L.; van Coevorden, F. Primary retroperitoneal myxoid/round cell liposarcoma is a nonexisting disease: An immunohistochemical and molecular biological analysis. Mod. Pathol. 2009, 22, 223-231. [CrossRef]

63. Setsu, N.; Miyake, M.; Wakai, S.; Nakatani, F.; Kobayashi, E.; Chuman, H.; Hiraoka, N.; Kawai, A.; Yoshida, A. Primary retroperitoneal myxoid liposarcomas. Am. J. Surg. Pathol. 2016, 40, 1286-1290. [CrossRef]

64. Powers, M.P.; Wang, W.L.; Hernandez, V.S.; Patel, K.S.; Lev, D.C.; Lazar, A.J.; López-Terrada, D.H. Detection of myxoid liposarcoma-associated rearrangement variants including a newly identified breakpoint using an optimized RT-PCR assay. Mod. Pathol. 2010, 23, 1307-1315. [CrossRef]

65. Smith, T.A.; Easley, K.A.; Goldblum, J.R. Myxoid/round cell liposarcoma of the extremities. A clinicopathologic study of 29 cases with particular attention to extent of round cell liposarcoma. Am. J. Surg. Pathol. 1996, 20, 171-180. [CrossRef]

66. Moreau, L.C.; Turcotte, R.; Ferguson, P.; Wunder, J.; Clarkson, P.; Masri, B.; Isler, M.; Dion, N.; Werier, J.; Ghert, M.; et al. Canadian Orthopaedic Oncology Society(CANOOS). Myxoid $\backslash$ round cell liposarcoma (MRCLS) revisited: An analysis of 418 primarily managed cases. Ann. Surg. Oncol. 2012, 19, 1081-1088. [CrossRef]

67. Baranov, E.; McBride, M.J.; Bellizzi, A.M.; Ligon, A.H.; Fletcher, C.D.M.; Kadoch, C.; Hornick, J.L. A novel SS18-SSX fusion-specific antibody for the diagnosis of synovial sarcoma. Am. J. Surg. Pathol. 2020, 44, 922-933. [CrossRef] [PubMed]

68. Dry, S.M.; Fröhling, S. Leiomyosacroma. In WHO Classification of Tumours. Soft Tissue and Bone Tumours, 5th ed.; The WHO Classification of Tumours Editorial Board, Ed.; IARC Press: Lyon, France, 2020; pp. 195-197.

69. Wile, A.G.; Evans, H.L.; Romsdahl, M.M. Leiomyosarcoma of soft tissue: A clinicopathologic study. Cancer 1981, 48, 1022-1032. [CrossRef]

70. Shmookler, B.M.; Lauer, D.H. Retroperitoneal leiomyosarcoma. A clinicopathologic analysis of 36 cases. Am. J. Surg. Pathol. 1983, 7, 269-280. [PubMed]

71. Farshid, G.; Pradhan, M.; Goldblum, J.; Weiss, S.W. Leiomyosarcoma of somatic soft tissues: A tumor of vascular origin with multivariate analysis of outcome in 42 cases. Am. J. Surg. Pathol. 2002, 26, 14-24. [CrossRef]

72. Fletcher, C.D.M.; Mertens, F. Inflammatory leiomyosarcoma. In WHO Classification of Tumours. Soft Tissue and Bone Tumours, 5th ed.; The WHO Classification of Tumours Editorial Board, Ed.; IARC Press: Lyon, France, 2020; pp. 193-194.

73. Watanabe, R.; Schafernak, K.T.; Soares, F.A. EBV-associated smooth muscle tumour. In WHO Classification of Tumours. Soft Tissue and Bone Tumours, 5th ed.; The WHO Classification of Tumours Editorial Board, Ed.; IARC Press: Lyon, France, 2020; pp. 190-192.

74. Rubin, B.P.; Fletcher, C.D. Myxoid leiomyosarcoma of soft tissue, an underrecognized variant. Am. J. Surg. Pathol. 2000, 24, 927-936. [CrossRef]

75. Yamamoto, T.; Minami, R.; Ohbayashi, C.; Inaba, M. Epithelioid leiomyosarcoma of the external deep soft tissue. Arch. Pathol. Lab. Med. 2002, 126, 468-470. [CrossRef] [PubMed]

76. Oda, Y.; Miyajima, K.; Kawaguchi, K.; Tamiya, S.; Oshiro, Y.; Hachitanda, Y.; Oya, M.; Iwamoto, Y.; Tsuneyoshi, M. Pleomorphic leiomyosarcoma: Clinicopathologic and immunohistochemical study with special emphasis on its distinction from ordinary leiomyosarcoma and malignant fibrous histiocytoma. Am. J. Surg. Pathol. 2001, 25, 1030-1038. [CrossRef]

77. Chen, E.; O'Connell, F.; Fletcher, C.D. Dedifferentiated leiomyosarcoma: Clinicopathological analysis of 18 cases. Histopathology 2011, 59, 1135-1143. [CrossRef]

78. Hornick, J.L.; Fletcher, C.D. Criteria for malignancy in nonvisceral smooth muscle tumors. Ann. Diagn. Pathol. 2003, 7, 60-66. [CrossRef]

79. Weiss, S.W. Smooth muscle tumors of soft tissue. Adv. Anat. Pathol. 2002, 9, 351-359. [CrossRef]

80. Cyril, F.; Montgomery, E.A.; Thway, K. Biopsy Interpretation of Soft Tissue Tumors, 2nd ed.; Wolters Kluwer: Philadelphia, PA, USA, 2016; pp. 134-135. 
81. Iwata, J.; Fletcher, C.D. Immunohistochemical detection of cytokeratin and epithelial membrane antigen in leiomyosarcoma: A systematic study of 100 cases. Pathol. Int. 2000, 50, 7-14. [CrossRef]

82. Demicco, E.G.; Fritchie, K.J.; Han, A. Solitary fibrous tumour. In WHO Classification of Tumours. Soft Tissue and Bone Tumours, 5th ed.; The WHO Classification of Tumours Editorial Board, Ed.; IARC Press: Lyon, France, 2020; pp. 104-108.

83. Yamada, K.; Abiko, K.; Kido, A.; Minamiguchi, S.; Horie, A.; Mandai, M. Solitary fibrous tumor arising from pelvic retroperitoneum: A report of two cases and a review of the literature. J. Obstet. Gynaecol. Res. 2019, 45, 1391-1397. [CrossRef] [PubMed]

84. Zhou, Y.; Chu, X.; Yi, Y.; Tong, L.; Dai, Y. Malignant solitary fibrous tumor in retroperitoneum: A case report and literature review. Medicine 2017, 96, e6373. [CrossRef] [PubMed]

85. Chmielecki, J.; Crago, A.M.; Rosenberg, M.; O'Connor, R.; Walker, S.R.; Ambrogio, L.; Auclair, D.; McKenna, A.; Heinrich, M.C.; Frank, D.A.; et al. Whole-exome sequencing identifies a recurrent NAB2-STAT6 fusion in solitary fibrous tumors. Nat. Genet. 2013, 45, 131-132. [CrossRef]

86. De Saint Aubain Somerhausen, N.; Rubin, B.P.; Fletcher, C.D. Myxoid solitary fibrous tumor: A study of seven cases with emphasis on differential diagnosis. Mod. Pathol. 1999, 12, 463-471. [PubMed]

87. Guillou, L.; Gebhard, S.; Coindre, J.M. Lipomatous hemangiopericytoma: A fat-containing variant of solitary fibrous tumor? Clinicopathologic, immunohistochemical, and ultrastructural analysis of a series in favor of a unifying concept. Hum. Pathol. 2000, 31, 1108-1115. [CrossRef] [PubMed]

88. Guillou, L.; Gebhard, S.; Coindre, J.M. Orbital and extraorbital giant cell angiofibroma: A giant cell-rich variant of solitary fibrous tumor? Clinicopathologic and immunohistochemical analysis of a series in favor of a unifying concept. Am. J. Surg. Pathol. 2000, 24, 971-979. [CrossRef]

89. Olson, N.J.; Linos, K. Dedifferentiated solitary fibrous tumor: A concise review. Arch. Pathol. Lab. Med. 2018, 142, 761-766. [CrossRef]

90. Demicco, E.G.; Wagner, M.J.; Maki, R.G.; Gupta, V.; Iofin, I.; Lazar, A.J.; Wang, W.L. Risk assessment in solitary fibrous tumors: Validation and refinement of a risk stratification model. Mod. Pathol. 2017, 30, 1433-1442. [CrossRef]

91. Creytens, D.; Ferdinande, L.; Van Dorpe, J. multifocal cytokeratin expression in a dedifferentiated solitary fibrous tumor with heterologous rhabdomyosarcomatous differentiation: A challenging diagnosis! Int. J. Surg. Pathol. 2018, 26, 423-427. [CrossRef]

92. Doyle, L.A.; Vivero, M.; Fletcher, C.D.; Mertens, F.; Hornick, J.L. Nuclear expression of STAT6 distinguishes solitary fibrous tumor from histologic mimics. Mod. Pathol. 2014, 27, 390-395. [CrossRef] [PubMed]

93. Doyle, L.A.; Tao, D.; Mariño-Enríquez, A. STAT6 is amplified in a subset of dedifferentiated liposarcoma. Mod. Pathol. 2014, 27, 1231-1237. [CrossRef] [PubMed]

94. Creytens, D.; Libbrecht, L.; Ferdinande, L. Nuclear expression of STAT6 in dedifferentiated liposarcomas with a solitary fibrous tumor-like morphology: A diagnostic pitfall. Appl. Immunohistochem. Mol. Morphol. 2015, 23, 462-463. [CrossRef] [PubMed]

95. Creytens, D. Malignant solitary fibrous tumour of the kidney with lymph node and liver metastases: Beware of STAT6 expression in dedifferentiated liposarcoma with a solitary fibrous tumour-like morphology. Pathology 2017, 49, 671. [CrossRef]

96. Yamamoto, H. Inflammatory myofibroblastic tumour. In WHO Classification of Tumours. Soft Tissue and Bone Tumours, 5th ed.; The WHO Classification of Tumours Editorial Board, Ed.; IARC Press: Lyon, France, 2020; pp. 109-111.

97. Coffin, C.M.; Watterson, J.; Priest, J.R.; Dehner, L.P. Extrapulmonary inflammatory myofibroblastic tumor (inflammatory pseudotumor). A clinicopathologic and immunohistochemical study of 84 cases. Am. J. Surg. Pathol. 1995, 19, 859-872. [CrossRef]

98. Koirala, R.; Shakya, V.C.; Agrawal, C.S.; Khaniya, S.; Pandey, S.R.; Adhikary, S.; Pathania, O.P. Retroperitoneal inflammatory myofibroblastic tumor. Am. J. Surg. 2010, 199, e17-e19. [CrossRef]

99. Antonescu, C.R.; Suurmeijer, A.J.; Zhang, L.; Sung, Y.S.; Jungbluth, A.A.; Travis, W.D.; Al-Ahmadie, H.; Fletcher, C.D.; Alaggio, R. Molecular characterization of inflammatory myofibroblastic tumors with frequent ALK and ROS1 gene fusions and rare novel RET rearrangement. Am. J. Surg. Pathol. 2015, 39, 957-967. [CrossRef] 
100. Alassiri, A.H.; Ali, R.H.; Shen, Y.; Lum, A.; Strahlendorf, C.; Deyell, R.; Rassekh, R.; Sorensen, P.H.; Laskin, J.; Marra, M.; et al. ETV6-NTRK3 is expressed in a subset of ALK-negative inflammatory myofibroblastic tumors. Am. J. Surg. Pathol. 2016, 40, 1051-1061. [CrossRef]

101. Coffin, C.M.; Hornick, J.L.; Fletcher, C.D. Inflammatory myofibroblastic tumor: Comparison of clinicopathologic, histologic, and immunohistochemical features including ALK expression in atypical and aggressive cases. Am. J. Surg. Pathol. 2007, 31, 509-520. [CrossRef]

102. Mariño-Enríquez, A.; Wang, W.L.; Roy, A.; Lopez-Terrada, D.; Lazar, A.J.; Fletcher, C.D.; Coffin, C.M.; Hornick, J.L. Epithelioid inflammatory myofibroblastic sarcoma: An aggressive intra-abdominal variant of inflammatory myofibroblastic tumor with nuclear membrane or perinuclear ALK. Am. J. Surg. Pathol. 2011, 35, 135-144. [CrossRef]

103. Zen, Y.; Onodera, M.; Inoue, D.; Kitao, A.; Matsui, O.; Nohara, T.; Namiki, M.; Kasashima, S.; Kawashima, A.; Matsumoto, Y.; et al. Retroperitoneal fibrosis: A clinicopathologic study with respect to immunoglobulin G4. Am. J. Surg. Pathol. 2009, 33, 1833-1839. [CrossRef] [PubMed]

104. Rudzinski, E.R. Embryonal rhabdomyosarcoma. In WHO Classification of Tumours. Soft Tissue and Bone Tumours, 5th ed.; The WHO Classification of Tumours Editorial Board, Ed.; IARC Press: Lyon, France, 2020; pp. 201-204.

105. Crist, W.M.; Raney, R.B.; Tefft, M.; Heyn, R.; Hays, D.M.; Newton, W.; Beltangady, M.; Maurer, H.M. Soft tissue sarcomas arising in the retroperitoneal space in children. A report from the Intergroup Rhabdomyosarcoma Study (IRS) Committee. Cancer 1985, 56, 2125-2132. [CrossRef]

106. Furlong, M.A.; Mentzel, T.; Fanburg-Smith, J.C. Pleomorphic rhabdomyosarcoma in adults: A clinicopathologic study of 38 cases with emphasis on morphologic variants and recent skeletal muscle-specific markers. Mod. Pathol. 2001, 14, 595-603. [CrossRef] [PubMed]

107. Nascimento, A.F.; Fletcher, C.D. Spindle cell rhabdomyosarcoma in adults. Am. J. Surg. Pathol. 2005, 29, 1106-1113.

108. Qualman, S.; Lynch, J.; Bridge, J.; Parham, D.; Teot, L.; Meyer, W.; Pappo, A. Prevalence and clinical impact of anaplasia in childhood rhabdomyosarcoma: A report from the Soft Tissue Sarcoma Committee of the Children's Oncology Group. Cancer 2008, 113, 3242-3247. [CrossRef] [PubMed]

109. Rudzinski, E.R.; Teot, L.A.; Anderson, J.R.; Moore, J.; Bridge, J.A.; Barr, F.G.; Gastier-Foster, J.M.; Skapek, S.X.; Hawkins, D.S.; Parham, D.M. Dense pattern of embryonal rhabdomyosarcoma, a lesion easily confused with alveolar rhabdomyosarcoma: A report from the Soft Tissue Sarcoma Committee of the Children's Oncology Group. Am. J. Clin. Pathol. 2013, 140, 82-90. [CrossRef] [PubMed]

110. Kohashi, K.; Bode-Lesniewska, B. Alveolar rhabdomyosarcoma. In WHO Classification of Tumours. Soft Tissue and Bone Tumours, 5th ed.; The WHO Classification of Tumours Editorial Board, Ed.; IARC Press: Lyon, France, 2020; pp. 205-208.

111. Montgomery, E.A.; Dry, S.M. Pleomorphic rhabdomyosarcoma. In WHO Classification of Tumours. Soft Tissue and Bone tumours, 5th ed.; The WHO Classification of Tumours Editorial Board, Ed.; IARC Press: Lyon, France, 2020; pp. 209-210.

112. Agaram, N.P.; Szuhai, K. Spindle cell/sclerosing rhabdomyosarcoma. In WHO Classification of Tumours. Soft Tissue and Bone Tumours, 5th ed.; The WHO Classification of Tumours Editorial Board, Ed.; IARC Press: Lyon, France, 2020; pp. 211-213.

113. Trombatore, C.; Rosario, C.; Giovanni, L.D.; Gaetano, M.; Giuseppe, P.; Antonio, D.C. Dedifferentiated liposarcoma of retroperitoneum with extensive osteosarcomatous component. Int. Surg. 2016, 101, 217-221. [CrossRef]

114. Davis, J.L.; Antonescu, C.R.; Bahrami, A. Infantile fibrosarcoma. In WHO Classification of Tumours. Soft Tissue and Bone Tumours, 5th ed.; The WHO Classification of Tumours Editorial Board, Ed.; IARC Press: Lyon, France, 2020; pp. 119-121.

115. Nielsen, G.P.; Chi, P. Malignant peripheral nerve sheath tumour. In WHO Classification of Tumours. Soft Tissue and Bone Tumours, 5th ed.; The WHO Classification of Tumours Editorial Board, Ed.; IARC Press: Lyon, France, 2020; pp. 254-257.

116. Ducatman, B.S.; Scheithauer, B.W.; Piepgras, D.G.; Reiman, H.M.; Ilstrup, D.M. Malignant peripheral nerve sheath tumors. A clinicopathologic study of 120 cases. Cancer 1986, 57, 2006-2021. [CrossRef] 
117. Kourea, H.P.; Bilsky, M.H.; Leung, D.H.; Lewis, J.J.; Woodruff, J.M. Subdiaphragmatic and intrathoracic paraspinal malignant peripheral nerve sheath tumors: A clinicopathologic study of 25 patients and 26 tumors. Cancer 1998, 82, 2191-2203. [CrossRef]

118. McMenamin, M.E.; Fletcher, C.D. Expanding the spectrum of malignant change in schwannomas: Epithelioid malignant change, epithelioid malignant peripheral nerve sheath tumor, and epithelioid angiosarcoma: A study of 17 cases. Am. J. Surg. Pathol. 2001, 25, 13-25. [CrossRef]

119. Ghali, V.S.; Gold, J.E.; Vincent, R.A.; Cosgrove, J.M. Malignant peripheral nerve sheath tumor arising spontaneously from retroperitoneal ganglioneuroma: A case report, review of the literature, and immunohistochemical study. Hum. Pathol. 1992, 23, 72-75. [CrossRef]

120. Van Haverbeke, C.; Ferdinande, L.; Verbeke, S.; Van Dorpe, J.; Creytens, D. Malignant peripheral nerve sheath tumour with heterologous liposarcomatous differentiation: Case report and review of the literature. Pathology 2018, 50, 475-478. [CrossRef]

121. Laskin, W.B.; Weiss, S.W.; Bratthauer, G.L. Epithelioid variant of malignant peripheral nerve sheath tumor (malignant epithelioid schwannoma). Am. J. Surg. Pathol. 1991, 15, 1136-1145. [CrossRef] [PubMed]

122. Miettinen, M.M.; Antonescu, C.R.; Fletcher, C.D.M.; Kim, A.; Lazar, A.J.; Quezado, M.M.; Reilly, K.M.; Stemmer-Rachamimov, A.; Stewart, D.R.; Viskochil, D.; et al. Histopathologic evaluation of atypical neurofibromatous tumors and their transformation into malignant peripheral nerve sheath tumor in patients with neurofibromatosis 1-A consensus overview. Hum. Pathol. 2017, 67, 1-10. [CrossRef] [PubMed]

123. Schaefer, I.M.; Fletcher, C.D.; Hornick, J.L. Loss of H3K27 trimethylation distinguishes malignant peripheral nerve sheath tumors from histologic mimics. Mod. Pathol. 2016, 29, 4-13. [CrossRef] [PubMed]

124. Hornick, J.L.; Nielsen, G.P. Beyond "Triton": Malignant peripheral nerve sheath tumors with complete heterologous rhabdomyoblastic differentiation mimicking spindle cell rhabdomyosarcoma. Am. J. Surg. Pathol. 2019, 43, 1323-1330. [CrossRef] [PubMed]

125. Yamashita, K.; Hameed, M. Extraskeletal osteosarcoma. In WHO Classification of Tumours. Soft Tissue and Bone Tumours, 5th ed.; The WHO Classification of Tumours Editorial Board, Ed.; IARC Press: Lyon, France, 2020; pp. 224-225.

126. Orta, L.; Suprun, U.; Goldfarb, A.; Bleiweiss, I.; Jaffer, S. Radiation-associated extraskeletal osteosarcoma of the chest wall. Arch. Pathol. Lab. Med. 2006, 130, 198-200. [CrossRef]

127. Lidang Jensen, M.; Schumacher, B.; Myhre Jensen, O.; Steen Nielsen, O.; Keller, J. Extraskeletal osteosarcomas: A clinicopathologic study of 25 cases. Am. J. Surg. Pathol. 1998, 22, 588-594. [CrossRef]

128. Bane, B.L.; Evans, H.L.; Ro, J.Y.; Carrasco, C.H.; Grignon, D.J.; Benjamin, R.S.; Ayala, A.G. Extraskeletal osteosarcoma. A clinicopathologic review of 26 cases. Cancer 1990, 65, 2762-2770. [CrossRef]

129. Yamashita, K.; Kohashi, K.; Yamada, Y.; Nishida, Y.; Urakawa, H.; Oda, Y.; Toyokuni, S. Primary extraskeletal osteosarcoma: A clinicopathological study of 18 cases focusing on MDM2 amplification status. Hum. Pathol. 2017, 63, 63-69. [CrossRef]

130. Conner, J.R.; Hornick, J.L. SATB2 is a novel marker of osteoblastic differentiation in bone and soft tissue tumours. Histopathology 2013, 63, 36-49. [CrossRef] [PubMed]

131. Machado, I.; Navarro, S.; Picci, P.; Llombart-Bosch, A. The utility of SATB2 immunohistochemical expression in distinguishing between osteosarcomas and their malignant bone tumor mimickers, such as Ewing sarcomas and chondrosarcomas. Pathol. Res. Pract. 2016, 212, 811-816. [CrossRef] [PubMed]

132. Patel, R.M.; Weiss, S.W.; Folpe, A.L. Heterotopic mesenteric ossification: A distinctive pseudosarcoma commonly associated with intestinal obstruction. Am. J. Surg. Pathol. 2006, 30, 119-122. [CrossRef] [PubMed]

133. Magro, G.; Salvatorelli, L.; Puzzo, L.; Musumeci, G.; Bisceglia, M.; Parenti, R. Oncofetal expression of Wilms' tumor 1 (WT1) protein in human fetal, adult and neoplastic skeletal muscle tissues. Acta Histochem. 2015, 117, 492-504. [CrossRef] [PubMed]

134. Winnepenninckx, V.; De Vos, R.; Debiec-Rychter, M.; Samson, I.; Brys, P.; Hagemeijer, A.; Sciot, R. Calcifying/ossifying synovial sarcoma shows $\mathrm{t}(\mathrm{X} ; 18)$ with SSX2 involvement and mitochondrial calcifications. Histopathology 2001, 38, 141-145. [CrossRef]

135. Suurmeijer, A.J.H.; Ladanyi, M.; Nielsen, T.O. Synovial sarcoma. In WHO Classification of Tumours. Soft Tissue and Bone Tumours, 5th ed.; The WHO Classification of Tumours Editorial Board, Ed.; IARC Press: Lyon, France, 2020; pp. 290-293. 
136. Sultan, I.; Rodriguez-Galindo, C.; Saab, R.; Yasir, S.; Casanova, M.; Ferrari, A. Comparing children and adults with synovial sarcoma in the surveillance, epidemiology, and end results program, 1983 to 2005: An analysis of 1268 patients. Cancer 2009, 115, 3537-3547. [CrossRef]

137. Makhlouf, H.R.; Ahrens, W.; Agarwal, B.; Dow, N.; Marshalleck, J.J.; Lee, E.L.; Dotto, J.E.; Hui, P.; Sobin, L.H.; Oliveira, A.; et al. Synovial sarcoma of the stomach: A clinicopathologic, immunohistochemical, and molecular genetic study of 10 cases. Am. J. Surg. Pathol. 2008, 32, 275-281. [CrossRef]

138. Schoolmeester, J.K.; Cheville, J.C.; Folpe, A.L. Synovial sarcoma of the kidney: A clinicopathologic, immunohistochemical, and molecular genetic study of 16 cases. Am. J. Surg. Pathol. 2014, 38, 60-65. [CrossRef]

139. Fisher, C.; Folpe, A.L.; Hashimoto, H.; Weiss, S.W. Intra-abdominal synovial sarcoma: A clinicopathological study. Histopathology 2004, 45, 245-253. [CrossRef]

140. Van de Rijn, M.; Barr, F.G.; Xiong, Q.B.; Hedges, M.; Shipley, J.; Fisher, C. Poorly differentiated synovial sarcoma: An analysis of clinical, pathologic, and molecular genetic features. Am. J. Surg. Pathol. 1999, 23, 106-112. [CrossRef]

141. Foo, W.C.; Cruise, M.W.; Wick, M.R.; Hornick, J.L. Immunohistochemical staining for TLE1 distinguishes synovial sarcoma from histologic mimics. Am. J. Clin. Pathol. 2011, 135, 839-844. [CrossRef] [PubMed]

142. Amary, M.F.; Berisha, F.; Bernardi Fdel, C.; Herbert, A.; James, M.; Reis-Filho, J.S.; Fisher, C.; Nicholson, A.G.; Tirabosco, R.; Diss, T.C.; et al. Detection of SS18-SSX fusion transcripts in formalin-fixed paraffin-embedded neoplasms: Analysis of conventional RT-PCR, qRT-PCR and dual color FISH as diagnostic tools for synovial sarcoma. Mod. Pathol. 2007, 20, 482-496. [CrossRef] [PubMed]

143. Agaram, N.P.; Antonescu, C.R.; Ladanyi, M. Desmoplasic small round cell tumours. In WHO Classification of Tumours. Soft Tissue and Bone Tumours, 5th ed.; The WHO Classification of Tumours Editorial Board, Ed.; IARC Press: Lyon, France, 2020; pp. 306-308.

144. Gerald, W.; Rosai, J. Case 2. Desmoplastic small cell tumor with divergent differentiation. Pediatr. Pathol. 1989, 9, 177-183. [CrossRef]

145. Ordóñez, N.G. Desmoplastic small round cell tumor: I: A histopathologic study of 39 cases with emphasis on unusual histological patterns. Am. J. Surg. Pathol. 1998, 22, 1303-1313. [CrossRef] [PubMed]

146. Lae, M.E.; Roche, P.C.; Jin, L.; Lloyd, R.V.; Nascimento, A.G. Desmoplastic small round cell tumor: A clinicopathologic, immunohistochemical, and molecular study of 32 tumors. Am. J. Surg. Pathol. 2002, 26, 823-835. [CrossRef] [PubMed]

147. Subbiah, V.; Lamhamedi-Cherradi, S.E.; Cuglievan, B.; Menegaz, B.A.; Camacho, P.; Huh, W.; Ramamoorthy, V.; Anderson, P.M.; Pollock, R.E.; Lev, D.C.; et al. Multimodality treatment of desmoplastic small round cell tumor: Chemotherapy and complete cytoreductive surgery improve patient survival. Clin. Cancer Res. 2018, 24, 4865-4873. [CrossRef]

148. Pasquinelli, G.; Montanaro, L.; Martinelli, G.N. Desmoplastic small round-cell tumor: A case report on the large cell variant with immunohistochemical, ultrastructural, and molecular genetic analysis. Ultrastruct. Pathol. 2000, 24, 333-337. [CrossRef]

149. Thway, K.; Noujaim, J.; Zaidi, S.; Miah, A.B.; Benson, C.; Messiou, C.; Jones, R.L.; Fisher, C. Desmoplastic small round cell tumor: Pathology, genetics, and potential therapeutic strategies. Int. J. Surg. Pathol. 2016, 24, 672-684. [CrossRef]

150. Barnoud, R.; Sabourin, J.C.; Pasquier, D.; Ranchère, D.; Bailly, C.; Terrier-Lacombe, M.J.; Pasquier, B. Immunohistochemical expression of WT1 by desmoplastic small round cell tumor: A comparative study with other small round cell tumors. Am. J. Surg. Pathol. 2000, 24, 830-836. [CrossRef]

151. Hung, Y.P.; Lee, J.P.; Bellizzi, A.M.; Hornick, J.L. PHOX2B reliably distinguishes neuroblastoma among small round blue cell tumours. Histopathology 2017, 71, 786-794. [CrossRef]

152. Doyle, L.A.; Argani, P.; Hornick, J.L. PEComa. In WHO Classification of Tumours. Soft Tissue and Bone Tumours, 5th ed.; The WHO Classification of Tumours Editorial Board, Ed.; IARC Press: Lyon, France, 2020; pp. 312-314.

153. Folpe, A.L.; Mentzel, T.; Lehr, H.A.; Fisher, C.; Balzer, B.L.; Weiss, S.W. Perivascular epithelioid cell neoplasms of soft tissue and gynecologic origin: A clinicopathologic study of 26 cases and review of the literature. Am. J. Surg. Pathol. 2005, 29, 1558-1575. [CrossRef] [PubMed] 
154. Doyle, L.A.; Hornick, J.L.; Fletcher, C.D. PEComa of the gastrointestinal tract: Clinicopathologic study of 35 cases with evaluation of prognostic parameters. Am. J. Surg. Pathol. 2013, 37, 1769-1782. [CrossRef] [PubMed]

155. Hornick, J.L.; Fletcher, C.D. Sclerosing PEComa: Clinicopathologic analysis of a distinctive variant with a predilection for the retroperitoneum. Am. J. Surg. Pathol. 2008, 32, 493-501. [CrossRef] [PubMed]

156. Larque, A.B.; Kradin, R.L.; Chebib, I.; Nielsen, G.P.; Selig, M.K.; Thiele, E.A.; Stemmer-Rachamimov, A.; Bredella, M.A.; Kurzawa, P.; Deshpande, V. Fibroma-like PEComa: A tuberous sclerosis complex-related lesion. Am. J. Surg. Pathol. 2018, 42, 500-505. [CrossRef]

157. Folpe, A.L.; Kwiatkowski, D.J. Perivascular epithelioid cell neoplasms: Pathology and pathogenesis. Hum. Pathol. 2010, 41, 1-15. [CrossRef]

158. Argani, P.; Aulmann, S.; Illei, P.B.; Netto, G.J.; Ro, J.; Cho, H.Y.; Dogan, S.; Ladanyi, M.; Martignoni, G.; Goldblum, J.R.; et al. A distinctive subset of PEComas harbors TFE3 gene fusions. Am. J. Surg. Pathol. 2010, 34, 1395-1406. [CrossRef]

159. Dei Tos, A.P.; Mertens, F.; Pillay, N. Undifferentiated sarcoma. In WHO Classification of Tumours. Soft Tissue and Bone Tumours, 5th ed.; The WHO Classification of Tumours Editorial Board, Ed.; IARC Press: Lyon, France, 2020; pp. 318-320.

160. Fletcher, C.D. Undifferentiated sarcomas: What to do? And does it matter? A surgical pathology perspective. Ultrastruct. Pathol. 2008, 32, 31-36. [CrossRef]

161. Laskin, W.B.; Silverman, T.A.; Enzinger, F.M. Postradiation soft tissue sarcomas. An analysis of 53 cases. Cancer 1988, 62, 2330-2340. [CrossRef]

162. Fletcher, C.D.; Gustafson, P.; Rydholm, A.; Willén, H.; Akerman, M. Clinicopathologic re-evaluation of 100 malignant fibrous histiocytomas: Prognostic relevance of subclassification. J. Clin. Oncol. 2001, 19, 3045-3050. [CrossRef]

163. Deyrup, A.T.; Haydon, R.C.; Huo, D.; Ishikawa, A.; Peabody, T.D.; He, T.C.; Montag, A.G. Myoid differentiation and prognosis in adult pleomorphic sarcomas of the extremity: An analysis of 92 cases. Cancer 2003, 98, 805-813. [CrossRef]

164. Chung, L.; Lau, S.K.; Jiang, Z.; Loera, S.; Bedel, V.; Ji, J.; Weiss, L.M.; Chu, P.G. Overlapping features between dedifferentiated liposarcoma and undifferentiated high-grade pleomorphic sarcoma. Am. J. Surg. Pathol. 2009, 33, 1594-1600. [CrossRef] [PubMed]

165. De Álava, E.; Lessnick, S.L.; Stamenkovic, I. Ewing sarcoma. In WHO Classification of Tumours. Soft tissue and bone tumours, 5th ed.; The WHO Classification of Tumours Editorial Board, Ed.; IARC Press: Lyon, France, 2020; pp. 323-325.

166. Rud, N.P.; Reiman, H.M.; Pritchard, D.J.; Frassica, F.J.; Smithson, W.A. Extraosseous Ewing's sarcoma. A study of 42 cases. Cancer 1989, 64, 1548-1553. [CrossRef]

167. Cash, T.; McIlvaine, E.; Krailo, M.D.; Lessnick, S.L.; Lawlor, E.R.; Laack, N.; Sorger, J.; Marina, N.; Grier, H.E.; Granowetter, L.; et al. Comparison of clinical features and outcomes in patients with extraskeletal versus skeletal localized Ewing sarcoma: A report from the Children's Oncology Group. Pediatr. Blood Cancer 2016, 63, 1771-1779. [CrossRef]

168. Jimenez, R.E.; Folpe, A.L.; Lapham, R.L.; Ro, J.Y.; O'Shea, P.A.; Weiss, S.W.; Amin, M.B. Primary Ewing's sarcoma/primitive neuroectodermal tumor of the kidney: A clinicopathologic and immunohistochemical analysis of 11 cases. Am. J. Surg. Pathol. 2002, 26, 320-327. [CrossRef] [PubMed]

169. Movahedi-Lankarani, S.; Hruban, R.H.; Westra, W.H.; Klimstra, D.S. Primitive neuroectodermal tumors of the pancreas: A report of seven cases of a rare neoplasm. Am. J. Surg. Pathol. 2002, 26, 1040-1047. [CrossRef]

170. Ulusan, S.; Koc, Z.; Canpolat, E.T.; Colakoglu, T. Radiological findings of primary retroperitoneal Ewing sarcoma. Acta Radiol. 2007, 48, 814-818. [CrossRef]

171. Spacek, J.; Kopeckova, K.; Kosina, J.; Pacovsky, J.; Petera, J.; Krbal, L.; Mrhalová, M.; Dvorak, P.; Brod'ák, M. Primary retroperitoneal Ewing's sarcoma. Rozhl. Chir. 2019, 98, 121-124.

172. Zhang, J.; Walsh, M.F.; Wu, G.; Edmonson, M.N.; Gruber, T.A.; Easton, J.; Hedges, D.; Ma, X.; Zhou, X.; Yergeau, D.A.; et al. Germline mutations in predisposition genes in pediatric cancer. N. Engl. J. Med. 2015, 373, 2336-2346. [CrossRef] 
173. Llombart-Bosch, A.; Machado, I.; Navarro, S.; Bertoni, F.; Bacchini, P.; Alberghini, M.; Karzeladze, A.; Savelov, N.; Petrov, S.; Alvarado-Cabrero, I.; et al. Histological heterogeneity of Ewing's sarcoma/PNET: An immunohistochemical analysis of 415 genetically confirmed cases with clinical support. Virchows Arch. 2009, 455, 397-411. [CrossRef]

174. Machado, I.; Noguera, R.; Mateos, E.A.; Calabuig-Fariñas, S.; López, F.I.; Martínez, A.; Navarro, S.; Llombart-Bosch, A. The many faces of atypical Ewing's sarcoma. A true entity mimicking sarcomas, carcinomas and lymphomas. Virchows Arch. 2011, 458, 281-290. [CrossRef]

175. Bishop, J.A.; Alaggio, R.; Zhang, L.; Seethala, R.R.; Antonescu, C.R. Adamantinoma-like Ewing family tumors of the head and neck: A pitfall in the differential diagnosis of basaloid and myoepithelial carcinomas. Am. J. Surg. Pathol. 2015, 39, 1267-1274. [CrossRef]

176. Yoshida, A.; Sekine, S.; Tsuta, K.; Fukayama, M.; Furuta, K.; Tsuda, H. NKX2.2 is a useful immunohistochemical marker for Ewing sarcoma. Am. J. Surg. Pathol. 2012, 36, 993-999. [CrossRef] [PubMed]

177. Wang, W.L.; Patel, N.R.; Caragea, M.; Hogendoorn, P.C.; López-Terrada, D.; Hornick, J.L.; Lazar, A.J. Expression of ERG, an Ets family transcription factor, identifies ERG-rearranged Ewing sarcoma. Mod. Pathol. 2012, 25, 1378-1383. [CrossRef] [PubMed]

178. Magro, G.; Salvatorelli, L.; Alaggio, R.; D’Agata, V.; Nicoletti, F.; Di Cataldo, A.; Parenti, R. Diagnostic utility of cyclin D1 in the diagnosis of small round blue cell tumors in children and adolescents. Hum. Pathol. 2017, 60, 58-65. [CrossRef] [PubMed]

179. Antonescu, C.R.; Yoshida, A. CIC-rearranged sarcoma. In WHO Classification of Tumours. Soft Tissue and Bone Tumours, 5th ed.; The WHO Classification of Tumours Editorial Board, Ed.; IARC Press: Lyon, France, 2020; pp. 330-332.

180. Antonescu, C.R.; Puls, F.; Tirode, F. Sarcoma with BCOR genetic alterations. In WHO Classification of Tumours. Soft Tissue and Bone Tumours, 5th ed.; The WHO Classification of Tumours Editorial Board, Ed.; IARC Press: Lyon, France, 2020; pp. 333-335.

181. Mentzel, T.; Calonje, E.; Wadden, C.; Camplejohn, R.S.; Beham, A.; Smith, M.A.; Fletcher, C.D. Myxofibrosarcoma. Clinicopathologic analysis of 75 cases with emphasis on the low-grade variant. Am. J. Surg. Pathol. 1996, 20, 391-405. [CrossRef] [PubMed]

182. Rekhi, B.; Ingle, A.; Agarwal, M.; Puri, A.; Laskar, S.; Jambhekar, N.A. Alveolar soft part sarcoma 'revisited': Clinicopathological review of 47 cases from a tertiary cancer referral centre, including immunohistochemical expression of TFE3 in 22 cases and 21 other tumours. Pathology 2012, 44, 11-17. [CrossRef]

183. Meis-Kindblom, J.M.; Kindblom, L.G. Angiosarcoma of soft tissue: A study of 80 cases. Am. J. Surg. Pathol. 1998, 22, 683-697. [CrossRef]

184. Katabuchi, H.; Honda, R.; Tajima, T.; Ohtake, H.; Kageshita, T.; Ono, T.; Okamura, H. Clear cell sarcoma arising in the retroperitoneum. Int. J. Gynecol. Cancer 2002, 12, 124-127. [CrossRef]

185. Fukuda, T.; Ishikawa, H.; Ohnishi, Y.; Tachikawa, S.; Onizuka, S.; Sakashita, I. Extraskeletal myxoid chondrosarcoma arising from the retroperitoneum. Am. J. Clin. Pathol. 1986, 85, 514-519. [CrossRef]

186. Paal, E.; Miettinen, M. Retroperitoneal leiomyomas: A clinicopathologic and immunohistochemical study of 56 cases with a comparison to retroperitoneal leiomyosarcomas. Am. J. Surg. Pathol. 2001, 25, 1355-1363. [CrossRef]

(C) 2020 by the authors. Licensee MDPI, Basel, Switzerland. This article is an open access article distributed under the terms and conditions of the Creative Commons Attribution (CC BY) license (http://creativecommons.org/licenses/by/4.0/). 